\title{
Cholesterol and sphingomyelin are critical for Fcy receptor-mediated phagocytosis of Cryptococcus neoformans by macrophages
}

Arielle M. Bryan ${ }^{1 \star \S}$, Jeehyun Karen You ${ }^{1 \star \S}$, Guangtao $\mathrm{Li}^{2}, \mathrm{JiHyun}_{\mathrm{Kim}}^{2 \S}$, Ashutosh Singh ${ }^{1 \S}$, Johannes Morstein ${ }^{3 \S}$, Dirk Trauner ${ }^{3}$, Nívea Pereira de Sá ${ }^{1}$, Tyler G. Normile ${ }^{1}$, Amir M. Farnoud ${ }^{1 \S}$, Erwin London ${ }^{2}$, Maurizio Del Poeta $^{1,4,5 \text { a }}$

${ }^{1}$ Department of Microbiology and Immunology, Stony Brook University, Stony Brook, NY, USA

${ }^{2}$ Department of Biochemistry and Cell Biology, Stony Brook University, Stony Brook, NY, USA

${ }^{3}$ Department of Chemistry, New York University, New York, NY, USA

${ }^{4}$ Division of Infectious Diseases, Stony Brook University, Stony Brook, NY, USA

${ }^{5}$ Veteran Affairs Medical Center, Northport, NY, USA

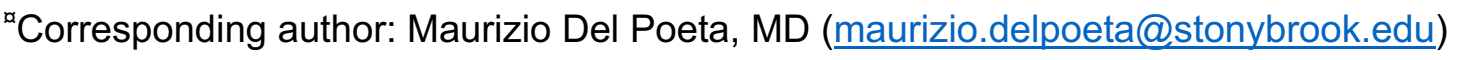

§Present address:

AMB: Ingenious Targeting Laboratory, Ronkonkoma, NY, USA

JKY: Case Western Reserve University, Cleveland, OH, USA

JHK: National Institute of Diabetes and Digestive and Kidney Diseases, National Institutes of Health, Bethesda, MD, USA

AS: Department of Biochemistry, University of Lucknow, Lucknow, Uttar Pradesh, India

JM: Department of Cellular and Molecular Pharmacology and Howard Hughes Medical Institute, University of California, San Francisco, California, USA.

AMF: Department of Chemical and Biomolecular Engineering, Ohio University, Athens, OH, USA

${ }^{*} \mathrm{AMB}$ and JKY are co-first authors and contributed equally.

Running title: Lipid rafts are critical for phagocytosis of C. neoformans

Keywords: lipid raft, cholesterol, sphingomyelin, Fc-gamma receptor, phagocytosis, macrophage, fungi

\section{Abstract}

Cryptococcus neoformans is a fungal pathogen that causes life-threatening meningoencephalitis in lymphopenic patients. Pulmonary macrophages comprise the first line of host defense upon inhalation of fungal spores, whereby macrophages either aid in clearance or serve as a niche for its dissemination. Given that macrophages play a key role in the outcome of a cryptococcal infection, it is crucial to understand factors that mediate phagocytosis of $C$. neoformans. Since lipid rafts (high order plasma membrane domains enriched in cholesterol and sphingomyelin) have been implicated in facilitating phagocytosis, we evaluated whether these ordered domains govern macrophages' ability to phagocytose $C$. neoformans. We found that cholesterol or sphingomyelin depletion resulted in significantly deficient IgG-mediated phagocytosis of the fungus. Moreover, repletion of macrophage cells with a raftpromoting sterol (7-dehydrocholesterol) rescued this phagocytic deficiency while a raft-inhibiting sterol (coprostanol) significantly decreased IgG-mediated phagocytosis of $C$. neoformans. Using a photoswitchable sphingomyelin (AzoSM), we observed that the raft-promoting conformation (trans-AzoSM) resulted in efficient phagocytosis 
whereas raft-inhibiting conformation (cis-AzoSM) significantly blunted phagocytosis in a reversible manner. We observed that the effect on phagocytosis may be mediated by facilitating Fcy receptor (FcyR) function, whereby IgG immune complexes cross-link to FcyRIII, resulting in tyrosine phosphorylation of FcR Y-subunit (FcRY), an important accessory protein in the FcyR signaling cascade. Correspondingly, cholesterol or sphingomyelin depletion resulted in decreased FcRy phosphorylation. Repletion with 7dehydrocholesterol restored phosphorylation, whereas repletion with coprostanol showed FcRy phosphorylation comparable to unstimulated cells. Together, these data suggest that lipid rafts are critical for facilitating FcyRIII-mediated phagocytosis of $C$. neoformans.

\section{Introduction}

Cryptococcus spp. are major opportunistic fungal pathogens that cause life-threatening meningoencephalitis in immunocompromised individuals $(1,2)$. Cryptococcus neoformans has been reported to cause approximately 223,100 cases of meningitis globally, resulting in 181,000 deaths every year (3). C. neoformans mediated host damage at the molecular and cellular level results in deficient immune effector cell function, disruption of endothelial barriers, and dissemination (4). Despite the substantial morbidity and mortality associated with cryptococcal meningoencephalitis, there is still much that is unknown about the delicate interactions between host immune cells and fungal pathogens like C. neoformans.

Pulmonary macrophages comprise the first line of host defense in response to $\mathrm{C}$. neoformans, as infection begins with inhalation of fungal spores commonly found in urban environments. A healthy host can typically kill and clear the pathogen. However, the fungus can be a facultative intracellular pathogen that survive within macrophages in immunocompromised individuals (e.g., HIV and AIDS patients) (2,5). In these cases, the macrophages can serve as a niche for the replication of the pathogen and may facilitate its dissemination to the central nervous system where the disease becomes fatal (6-9). C. neoformans can impair mitochondrial function, alter protein synthesis, or undergo non-lytic exocytosis from macrophages (10-13). Macrophages may even deliver the fungus directly into the meninges, helping the yeast to cross the blood brain barrier via the "Trojan horse" model (14-17). Given that macrophages can determine the outcome of a cryptococcal infection, it is crucial to understand the factors that mediate phagocytosis of $C$. neoformans, a major function of macrophages.

Phagocytosis is a process by which extracellular entities are internalized by phagocytic cells. It is a key weapon in the immune system's arsenal to defend against pathogens, but the process may often be subverted by pathogens to allow for internalization and dissemination throughout the body (18). Phagocytosis is mediated by several signaling events that result in attachment and engulfment via rearrangements of the host cell's cytoskeleton. 'Professional' phagocytes are able to recognize and bind to opsonins on the surface of the invading pathogen to signal for attachment and the formation of lamellipodia, which engulf the pathogen and form a phagosome (2). Macrophages are highly specialized cells that carry out protective functions that include seeking out and eliminating disease causing agents, repairing damaged tissues, and mediating inflammation, most of these through the process of phagocytosis $(18,19)$.

Previous work in other pathogen systems point to lipid rafts formed by cholesterol and sphingomyelin as having an important role to play in phagocytosis (20-26). In fact, a recent study implicated lipid rafts in the phagocytic response to Aspergillus fumigatus, another opportunistic fungal pathogen (27). Cholesterol is the single most abundant lipid species in mammalian plasma membranes, comprising $25-50 \%$ of the cell membrane lipid content (28). It has been found to play a role in modulating the biophysical properties of membranes by changing their rigidity (29). Cholesterol and sphingolipids together form lipid microdomains within the membrane known as lipid rafts. Lipid rafts have been found to be involved in the formation of caveolae as well as activation of various signaling cascades, whereby domains favor specific protein-protein interactions (28-30). In fact, previous studies have implicated the role of rafts in immune receptor signaling (31). Given their small 
size, it is difficult to study lipid rafts in vivo. One useful way to study the role of lipid rafts is to alter their constituents. Cyclodextrins and sphingomyelinase have been found to deplete, replace, or alter lipids from host mammalian membranes and are commonly used to study the role of lipid rafts $(30,32-37)$.

In this study, several approaches were employed to alter cholesterol or sphingomyelin on the outer leaflet of the plasma membrane to examine how lipid rafts may play a role in phagocytosis of $C$. neoformans. We found that cholesterol and sphingomyelin are critical for IgG-mediated phagocytosis of $C$. neoformans. Moreover, repletion with domain-promoting sterols like cholesterol or 7dehydrocholesterol promoted efficient antibodymediated phagocytosis of the fungal cells, whereas domain-inhibiting sterols like coprostanol significantly reduced it. Using a photoswitchable sphingomyelin (AzoSM), we observed that the raftpromoting conformation (trans-AzoSM) resulted in efficient phagocytosis whereas raft-inhibiting conformation (cis-AzoSM) significantly blunted phagocytosis in a reversible manner. Mechanistically, we found that cholesterol and sphingomyelin enriched ordered domains may be important for the function of Fcy receptors, the class of immune receptors activated by IgG immune complexes. These findings provide more directed insights into the role of cholesterol and sphingomyelin-rich lipid rafts in mediating Fcy receptor activation and IgG-dependent phagocytosis of C. neoformans.

\section{Results}

Cholesterol or sphingomyelin depletion affects IgGmediated phagocytosis of $C$. neoformans

To investigate the role of cholesterol in phagocytosis of the fungal pathogen $C$. neoformans, we utilized methyl-beta-cyclodextrin $(M \beta C D)$ to deplete cholesterol from the membrane of murine macrophages prior to infection with antibody opsonized C. neoformans (38). We previously showed that treatment with $10 \mathrm{mM}$ or $30 \mathrm{mM} \mathrm{M \beta CD}$ depletes approximately $50 \%$ or $75 \%$ of the total cholesterol in the cells, respectively (38). Furthermore, $M \beta C D$ treatment did not significantly alter cell attachment or viability (38). Most importantly, cholesterol depletion resulted in a significant decrease in antibody-mediated phagocytosis of $C$. neoformans (38). This finding was recapitulated across two murine macrophage cell lines. Both alveolar (Figure 1A) and peritoneallyderived macrophages (J774.1, Figure S1A) showed significant deficiency in phagocytosing $C$. neoformans cells opsonized with an antiglucuronoxylomannan (GXM) IgG, an antibody specific to the cryptococcal capsule (39). When C. neoformans cells were instead opsonized with complement serum, phagocytosis was not affected (Figure 1C),

Given the collaborative role of cholesterol and sphingomyelin in lipid rafts, we examined the effect of depleting sphingomyelin on the plasma membrane of macrophages. One tool available for the study of sphingomyelin is recombinant bacterial sphingomyelinase (bSMase) which directly probes for the role of sphingomyelin on the plasma membrane, as the enzyme is too large to pass through the membrane (40). bSMase catalyzes the transformation of sphingomyelin into ceramide (Figure S2) and phosphorylcholine (40). To confirm sphingomyelin depletion, cellular lipids were analyzed following treatment with $250 \mathrm{mU} / \mathrm{ml}$ or 500 $\mathrm{mU} / \mathrm{ml}$ bSMase for 20 minutes. We found that treatment of macrophages with bSMase resulted in a significant decrease in C16 sphingomyelin, the most abundant sphingomyelin species detected in the cells, and a corresponding increase in C16 ceramide (Figure 2). To assess the effect of bSMase treatment on phagocytosis, cells were co-incubated with $C$. neoformans cells opsonized with anti-GXM IgG after bSMase treatment. We found a significant decrease in phagocytosis after bSMase treatment with both alveolar (MH-S, Figure 1B) and peritoneally-derived macrophages (J774.1, Figure S1B), albeit in a non-dose-dependent fashion. This effect was not observed when complement serum was used as an opsonin (Figure 1C). Together these data suggest that cholesterol and sphingomyelin are critical for IgG-mediated phagocytosis of $C$. neoformans. Moreover, our data suggest that this phenomenon is not cell line dependent.

Repletion with lipid raft altering sterols affects IgGmediated phagocytosis of C. neoformans

Given that multiple factors confound the use of $M \beta C D$ to deplete cholesterol from cell membranes, various sterols were added back into the cholesterol depleted macrophages to investigate the role of cholesterol in IgG-mediated phagocytosis of $C$. neoformans. M $B C D$ may remove cholesterol from both raft and non-raft domains, alter the distribution of cholesterol between plasma and 
intracellular membranes, and non-specifically extract phospholipids (41). To ascertain whether cholesterol sensitivity of IgG-dependent phagocytosis of $C$. neoformans could be attributed to lipid rafts, cholesterol depleted macrophages were repleted with cholesterol, 7dehydrocholesterol, or coprostanol (Figure S2). 7dehydrocholesterol has been shown to be significantly more domain-promoting than cholesterol, whereas coprostanol strongly inhibits domain formation $(36,42,43)$. We found that repletion with $0.2 \mathrm{mM}$ cholesterol in $2.5 \mathrm{mM} \mathrm{M \beta CD}$ resulted in a significant increase in total cellular cholesterol compared to the untreated control. On the other hand, repletion with $0.2 \mathrm{mM}$ 7dehydrocholesterol or $0.2 \mathrm{mM}$ coprostanol in $2.5 \mathrm{mM}$ $M \beta C D$ resulted in a significant decrease in cellular cholesterol and a marked increase in substituted sterol comparable to the cellular cholesterol for the untreated control (Figure 3A). When treated macrophages were co-incubated with $C$. neoformans cells opsonized with anti-GXM IgG, we found that we were able to restore phagocytosis by cholesterol or 7-dehydrocholesterol repletion, whereas coprostanol repletion did not restore phagocytosis (Figure 3B).

\section{Cholesterol, but not sphingomyelin digestion affects lipid nanodomain stability}

To assess how sterol depletion/repletion may affect lipid raft stability in macrophages, we evaluated ordered nanodomains (rafts) in giant plasma membrane vesicles (GPMVs) derived from macrophages through Förster resonance energy transfer (FRET). When rafts are present FRET donor and FRET acceptor become partially segregated in different (raft and non-raft) domains, and FRET decreases so the FRET donor is more fluorescent (i.e. $F / F_{0}$ increases ) As previously, we used the temperature at the which the value of $F / F_{0}$ is a minimum as an approximate temperature for the upper limit of when rafts were present, i.e. a measure of their thermal stability (36). We also used the total increase in $F / F_{0}$ relative to the value at which $F / F_{0}$ is a minimum in a sample as another rough measure of total raft formation over the entire temperature range.

GPMVs prepared from cholesterol-depleted macrophages showed a significant shift in nanodomain stability (Figure 4A, Table S1, raw unnormalized $F / F_{0}$ values for $F R E T$ data are shown in Figures S3A). The presence of detectable ordered nanodomains significantly decreased, with up to 20 ${ }^{\circ} \mathrm{C}$ decrease in $\mathrm{T}_{\text {end, }}$, the temperature at which ordered domains are completely melted (36). Upon repletion with cholesterol, detectable ordered nanodomains significantly increased compared to the untreated and cholesterol depleted macrophages with a corresponding recovery in $T_{\text {end }}$. As expected, repletion with 7-dehydrocholesterol resulted in significantly greater presence of detectable nanodomains as well as increased thermal stability (higher $\mathrm{T}_{\text {end }}$ compared to untreated control). On the other hand, repletion with coprostanol ablated both the presence of detectable ordered nanodomains and the GPMV thermal stability (Figure 4B, Table S1, raw unnormalized $\mathrm{F} / \mathrm{F}_{0}$ values for FRET data are shown in Figure S3B).

To ascertain whether sphingomyelin depletion alters lipid raft stability in macrophages, we also evaluated nanodomain stability in GPMVs derived from bSMase-treated macrophages. We found that neither 250 nor $500 \mathrm{mU} / \mathrm{ml}$ bSMase treatment altered nanodomain stability, with $\mathrm{T}_{\text {end }}$ and GPMV levels comparable to the untreated control (Figure S4, Table S1, raw unnormalized F/F $F_{0}$ values for FRET data are shown in Figure S4C). It should be noted that the lipid product of bSMase digestion, ceramide, is itself a raft-forming lipid, but one that alters the lipid composition (e.g. resulting in displacement of cholesterol from rafts) and properties of lipid rafts $(44,45)$.

Together these results not only suggest that the presence of ordered lipid domains mediate IgGdependent phagocytosis of $C$. neoformans, but that lipid domain stability is cholesterol-dependent.

Cholesterol or sphingomyelin depletion may affect structure of lipid rafts

EGFP-nakanori is a protein that labels cell surface domains in a sphingomyelin and cholesteroldependent manner. More specifically, nakanori only binds pre-existing sphingomyelin/cholesterol domains as it is unable to induce formation of sphingomyelin-cholesterol complexes (46). To examine whether cholesterol depletion or sphingomyelin depletion perturbs sphingomyelincholesterol complexes, macrophages were either treated with $M \beta C D$ or bSMase and labeled with EGFP-nakanori. Both cholesterol and sphingomyelin depletion resulted in marked decrease in EGFP-nakanori binding, suggesting successful perturbation of sphingomyelincholesterol complexes (Figure 5). These results suggest that $M \beta C D$ and bSMase treatment may potentially affect lipid raft structure independent of nanodomain stability. 
AzoSM can reversibly modulate IgG-mediated phagocytosis of $C$. neoformans

To better understand how sphingomyelin facilitates lgG-dependent phagocytosis of $C$. neoformans, we utilized a photoswitchable sphingomyelin. Photoswitchable lipids allow for the optical control of lipid function with high spatiotemporal resolution, enabling precise functional manipulations. They have been shown to modulate many aspects of membrane biophysics, including permeability, fluidity, lipid mobility and domain formation (47-49). Recently, photoswitchable sphingolipids have emerged as potent tools to investigate cellular physiology using optical control, including receptor-mediated signaling and immune function (50-53). We synthesized AzoSM, a C16:0 sphingomyelin derivative containing an isosteric azobenzene photoswitch following a design principle called 'azologization' . Optical control of photoswitchable sphingolipids is mediated through light exposure. UV light $(\lambda=365 \mathrm{~nm})$ isomerizes the azobenzene group from a trans to cis conformation whereas blue light $(\lambda=460 \mathrm{~nm})$ reverts $\sim 80 \%$ of AzoSM from a cis to trans conformation (Figure S2). UV light therefore introduces a kink into the fatty acyl tail to disrupt ordered domains while blue light promotes domain formation $(48,56)$. Using methyl-alpha-cyclodextrin (MaCD), endogenous sphingomyelin species in macrophages were exchanged for AzoSM. This method exchanges phospholipids but does not alter cell sterol (32). We found that MaCD effectively replaced $\quad 280 \%$ of endogenous C16:0 sphingomyelin, the most abundant species of sphingomyelin in MH-S murine macrophages, with AzoSM (Figure 6A). When macrophages were coincubated with $C$. neoformans cells opsonized with anti-GXM IgG immediately following AzoSM exchange (no light exposure), we observed phagocytosis comparable to untreated control cells. Interestingly, we found that UV light treatment prior to co-incubation with $C$. neoformans resulted in a significant decrease in phagocytosis. Moreover, UV light exposure immediately followed by blue light treatment prior to co-incubation with fungal cells partially restored phagocytosis (Figure 6B). Together these data suggest that sphingomyelindependent lipid domains may be critical for IgGmediated phagocytosis of $C$. neoformans.

\section{Alterations in rafts affect Fcy receptor function}

Since alterations in plasma membrane lipids only affected phagocytosis of $C$. neoformans opsonized with anti-GXM IgG, our data implicate a critical role for lipid rafts in Fcy receptor (FcyR) mediated phagocytosis. As the anti-GXM antibody falls in the $\operatorname{lgG} 1 \mathrm{~K}$ subclass, antibody-opsonized $C$. neoformans bind to FcyRIIB and III, the low-affinity receptors for moue IgG1 $(39,57)$. To assess whether lipid depletion treatments alter the amount of cell surface receptors, macrophages were probed for CD16/32, which recognizes FcyR II/III, and CD11b antibody, which recognizes complement receptor 3 , known to mediate uptake of serum opsonized $C$. neoformans (58). CD45 was used as a general leukocyte marker, which should not be affected by lipid altering treatments. Flow cytometry showed that neither CD16/32 or CD11b levels on the cell surface were affected by cholesterol depletion with M $\beta C D$ or sphingomyelin depletion with bSMase for either J774.1 or MH-S macrophages (Figure S5). We next probed whether FcyR function rather than abundance on the plasma membrane was affected by lipid depletion. Murine FcyRIII requires the association of the FcR $y$ subunit (FcRy) following IgG immune complex and receptor aggregation at the plasma membrane. The FcRy contains an immunoreceptor tyrosine-based activation motif (ITAM) that is required for cell activation (57). To investigate FcRy activation following IgG immune complex and FcyR cross-linking, we utilized the approach by Rittirsch et al (59). We observed tyrosine phosphorylation of FcRy in macrophages stimulated with BSA-lgG immune complexes (IgGICs) within 5 minutes, with the phospho-tyrosine levels subsiding 15 minutes after stimulation (Figure S6). We then probed for tyrosine phosphorylation of FcRy in macrophages following lipid altering treatments. We observed that both sphingomyelin depletion (Figure 5A \& B) and cholesterol depletion (Figure 5C \& D) resulted in reduced FcRy activation upon IgGIC stimulation. Interestingly, repletion with cholesterol or 7-dehydrocholesterol showed comparable FcRy activation to the untreated control, whereas repletion with coprostanol significantly ablated the FcRy activation upon IgGIC stimulation (Figure 6). Although nuanced, we also observed some decrease in FcR $\mathrm{y}$ chain phosphorylation following UV light exposure post-AzoSM exchange, which was partially rescued upon blue light exposure (Figure S7).

Together, these data suggest that cholesterol and sphingomyelin-dependent lipid rafts are critical for proper FcyR clustering upon IgG immune complex cross linking in order to initiate the FcRy-mediated signaling cascade essential for phagocytosis of IgG1-opsonized $C$. neoformans (60).

\section{Discussion}


In this study, we utilized various methods of lipid alteration to probe for the role of lipid rafts in phagocytosis of C. neoformans. Substituting either endogenous cholesterol with a raft inhibiting sterol (coprostanol) or endogenous sphingomyelin with domain perturbing sphingomyelin (cis-AzoSM) lead to a decrease in antibody-mediated phagocytosis of C. neoformans (Figure 8). Since depletion treatments perturbed sphingomyelin-cholesterol complexes and significantly affected the FcyRmediated cell signaling (as evidenced by decreased FcRy ITAM activation) without altering the amount of FcyR IIB and III localized to the cell surface, it appears that sphingomyelin and cholesteroldependent lipid rafts are critical for facilitating FcyR-mediated cell signaling and function. Lipid rafts do not appear to be critical for phagocytosis mediated by complement serum opsonization, which was not affected by cholesterol depletion or bSMase treatment. The importance of cholesteroldependent lipid rafts in FcyR function was further highlighted by the fact that repletion with cholesterol or 7-dehydrocholesterol (raft promoting sterols) resulted in proper FcRy ITAM activation, whereas repletion with coprostanol (raft inhibiting sterol) significantly reduced FcRy ITAM activation. Similarly, Indeed, a recent review highlights the importance of plasma membrane domains on IgG Fc receptor function (61). However, studies of FcyRIII have been limited to the human FcyRIIla expressed on natural killer cells. Furthermore, studies have been limited to cellular fractionation assays and confocal microscopy $(62,63)$. Although murine and human FcyR differ in terms of binding abilities and expression pattern, the function and signaling mechanism are conserved (57). As such, insights into how cholesterol and sphingomyelin, two key components of lipid rafts, alter membrane properties and affect FcyR function can have broader implications.

Lipid depletion is useful to investigate the role of key lipids in cellular processes. Given the physiological importance of cholesterol in the cell plasma membrane, $M \beta C D$ has become the most common means of modifying the cholesterol content, mainly through cholesterol extraction. However, cyclodextrins may remove cholesterol from both raft and non-raft domains, alter the distribution of cholesterol between plasma and intracellular membranes, and simultaneously extract phospholipids (41). As such, cholesterol substitution with sterol structural analogues has been utilized in several studies to evaluate specific sterol-protein interactions or changes to the physical properties of the lipid bilayer $(33,42,43,64,65)$. The key is substitution with an equivalent amount of another sterol without altering the total sterol level in cells (41). Although our cholesterol repletion increased total cellular sterol, it did not interfere with macrophages' ability to phagocytose or initiate FcyR signaling. When compared to 7-dehyrocholesterol or coprostanol repletion, nanodomain properties were consistent with raft formation.

bSMase is a useful tool to study the role of sphingomyelin depletion as well as ceramide accumulation on the plasma membrane. The effects of sphingomyelin digestion can be complex. Ceramides have been implicated in stabilizing sphingomyelin-rich domains (43). They can also displace cholesterol from rafts and from the plasma membrane $(44,68,69)$. Modifying ordered domain properties, therefore, can have pleiotropic consequences. Previous work in other pathogen systems suggested that ceramide-rich membrane rafts resulting from bSMase activity are critical for host defense, including receptor clustering $(70,71)$. Interestingly, ceramide-rich membrane rafts have also been implicated in FcyR signaling. Indeed, the presence of $\mathrm{C} 16$ ceramide at the cell surface has been suggested to precede and control FcyRII clustering and phosphorylation in rafts, acting as a negative regulator of IgG-dependent phagocytosis $(72,73)$. FcyRII is an inhibitory immune receptor containing an immunoreceptor tyrosine-based inhibitory motif (ITIM) (74). Given our bSMase treatment resulted in $\mathrm{C} 16 \mathrm{SM}$ depletion and a corresponding accumulation of $\mathrm{C} 16$ ceramide (Figure 2), aberrant FcyRII signaling may have contributed to the decrease in IgG-dependent phagocytosis of $C$. neoformans.

Given the complex, pleiotropic effects of bSMase treatment, AzoSM is a potent tool that permits direct control of lipid function and ordered domains with high spatiotemporal resolution. Together, sterol substitution and AzoSM exchange offer critical insights into the role of cholesterol and sphingomyelin-dependent lipid domains in mediating membrane receptor signaling. Interestingly, protein tyrosine phosphatases have been reported to be excluded from lipid rafts during antigen-activated IgE signaling mediated by Fce receptor I (FcERI) (66). In addition, a loss of insulin receptor accessibility to phosphatases when lipid raft levels are increased regulates its kinase activity (37). Consequently, exclusion of phosphatases from 
raft domains provides an amenable environment for efficient kinase activity and IgE signaling. Since FcyRIII and FceRI both require FcRy phosphorylation to initiate the signaling cascade (67), raft disruption in our studies may have resulted in aberrant phosphatase activity on FcRy to attenuate IgG signaling.

Together these data demonstrate that lipid raft formation, high membrane order, and domain structure are critical for FcyRIII function whereby disruption of lipid rafts interferes with the efficiency of FcyRIII signaling. Through this work, we provide direct evidence that cholesterol and sphingomyelin play a critical role in coordinating a phagocytic response to $C$. neoformans.

\section{Experimental procedures}

Cells, media, and reagents for lipid alteration

C. neoformans var. grubii serotype A strain H99 was used in this study. Fungal cells were grown in yeast nitrogenous base (YNB) medium containing $2 \%$ glucose, $\mathrm{pH} 7.2$, for 16 to 18 hours at $30^{\circ} \mathrm{C}$ with shaking before experiments. Alveolar macrophage cell line MH-S (ATCC CRL-2019) was cultured in complete RPMI-1640 (supplemented with 10\% FBS and $1 \%$ penicillin/streptomycin) at $37^{\circ} \mathrm{C}+5 \% \mathrm{CO}_{2}$. Peritoneal macrophage cell line J774.1 (ATCC TIB67 ) was cultured in complete high glucose DMEM (supplemented with 10\% FBS and 1\% penicillin/streptomycin). Macrophages were seeded at the following densities for experiments: $5 \times 10^{4}$ cells in $200 \mu \mathrm{l}$ per well for 96 -well plates (phagocytosis assay), $1 \times 10^{6}$ (lipid analysis) or 1.5 $x 10^{6}$ (flow cytometry) in $5 \mathrm{ml}$ per well for 6 -well plates, $1 \times 10^{6}$ (microscopy) in $5 \mathrm{ml}$ per $35 \mathrm{~mm}$ glass bottom dish, and $8.6 \times 10^{6}$

(immunoprecipitation/Western blot) or $1.5 \times 10^{7}$ (FRET) in $15 \mathrm{ml}$ for $100 \mathrm{~mm}$ dishes. Cells were allowed to adhere at $37^{\circ} \mathrm{C}+5 \% \mathrm{CO}_{2}$ overnight prior to commencing experiments. AzoSM was synthesized as previously described (55). Sphingomyelinase from Staphylococcus aureus (Sigma), methyl-beta-cyclodextrin (MßCD) (Sigma), cholesterol (Sigma), 7-dehydrocholesterol (Sigma), and coprostanol (Cayman Chemicals) used for lipid altering treatments were purchased.

\section{Preparation of sterol-loaded methyl-beta-} cyclodextrin $(M \beta C D)$
Sterol-loaded M $\beta C D$ solutions were prepared as previously described $(32,33)$. Briefly, sterols dissolved in chloroform were dried under nitrogen gas (N-EVAP, Organomation) followed by high vacuum for at least 1 hour (Savant SpeedVac, Thermo Fisher Scientific). They were then hydrated with $2.5 \mathrm{mM} \mathrm{M \beta CD}$ prepared in serum-free medium. Sterol-loaded M $\beta C D$ solutions were then sonicated (Bransonic Ultrasonic Baths, Branson) for 5 minutes until no visible particles remained. Next, the sterol-loaded M $\beta C D$ solutions were incubated at $55^{\circ} \mathrm{C}$ for 30 minutes then at $37^{\circ} \mathrm{C}$ overnight with shaking. Solutions were filtered through a $0.22 \mu \mathrm{m}$ polyethersulfone syringe filter (Millex-GP, Millipore Sigma) to remove undissolved sterol. Unless otherwise noted, the final solutions, assuming undissolved sterol was negligible, contained $0.2 \mathrm{mM}$ cholesterol, 7dehydrocholesterol, or coprostanol mixed with 2.5 $\mathrm{mM} M \beta C D$.

\section{Cholesterol depletion/sterol repletion using $M \beta C D$}

Cholesterol was depleted from macrophages using $M \beta C D$ as previously described (38). Briefly, macrophages were seeded as described above and allowed to adhere overnight at $37^{\circ} \mathrm{C}+5 \% \mathrm{CO}_{2}$. Macrophage monolayers were washed twice with 1x Dulbecco's phosphate buffered saline (DPBS). $10 \mathrm{mM}$ or $30 \mathrm{mM} M \beta C D$ solutions were prepared in serum-free media (DMEM for J774.1 cells and RPMI-1640 for MH-S cells) and added to macrophage monolayers as follows: $200 \mu \mathrm{l}$ for 96 well plates, $2 \mathrm{ml}$ for 6 -well plates or $35 \mathrm{~mm}$ dishes, and $5 \mathrm{ml}$ for $100 \mathrm{~mm}$ dishes. Cells were incubated in $\mathrm{M} \beta \mathrm{CD}$ solution for 30 minutes at $37^{\circ} \mathrm{C}+5 \% \mathrm{CO}_{2}$ with shaking. After removing the $\mathrm{M} \beta C D$ solution, cells were washed three times with $1 \times$ DPBS before processing for analysis.

For sterol repletion, cholesterol was first depleted from macrophages using $10 \mathrm{mM} \mathrm{M \beta CD} \mathrm{in}$ serum-free medium for 30 minutes $37^{\circ} \mathrm{C}+5 \% \mathrm{CO}_{2}$ with gentle shaking. The macrophage monolayers were then washed three times with 1x DPBS. Sterolloaded $M \beta C D$ solutions were added to the cells as follows: $200 \mu \mathrm{l}$ for 96 -well plates, $1 \mathrm{ml}$ for 6 -well plates or $35 \mathrm{~mm}$ dishes, and $2 \mathrm{ml}$ for $100 \mathrm{~mm}$ dishes. Cells were incubated at $37^{\circ} \mathrm{C}+5 \% \mathrm{CO}_{2}$ for 2 hours with gentle shaking. Macrophage monolayers were 
then washed four times with 1x DPBS before processing for analysis.

\section{Sphingomyelin depletion using bacterial sphingomyelinase}

To reduce sphingomyelin (SM) in the outer leaflet of the plasma membrane, macrophages were treated with bacterial sphingomyelinase (bSMase) to catalyze the transformation of sphingomyelin into ceramide and phosphorylcholine as previously described (40). Briefly, macrophages were seeded as described above and allowed to adhere overnight at $37^{\circ} \mathrm{C}+$ $5 \% \mathrm{CO}_{2}$. Macrophage monolayers were washed twice with 1x DPBS. 50, 100, 250, or $500 \mathrm{mU} / \mathrm{ml}$ bSMase solutions were prepared in serum-free media and added to macrophage monolayers as follows: $200 \mu \mathrm{l}$ for 96 -well plates, $2 \mathrm{ml}$ for 6 -well plates or $35 \mathrm{~mm}$ dishes, and $5 \mathrm{ml}$ for $100 \mathrm{~mm}$ dishes. Cells were incubated in bSMase solution for 20 minutes at $37^{\circ} \mathrm{C}+5 \% \mathrm{CO}_{2}$ with shaking.

Macrophage monolayers were then washed three times with 1x DPBS before processing for analysis.

\section{Preparation of AzoSM loaded methyl-alpha- cyclodextrin (MaCD)}

AzoSM was loaded into MaCD for sphingomyelin exchange as previously described $(32,36)$. Briefly, AzoSM dissolved in chloroform was dried under nitrogen gas (N-EVAP, ORganomation). The lipid was then resuspended in pre-warmed serum-free medium, vortexed vigorously, and incubated at $70^{\circ} \mathrm{C}$ for 5 minutes on a heat block. Next, the appropriate amount of MaCD was added to the solution to yield $40 \mathrm{mM}$ MaCD. To load AzoSM into MaCD, the solution was then incubated for 3045 minutes at $37^{\circ} \mathrm{C}+5 \% \mathrm{CO}_{2}$ with constant shaking until no visible particles remained. The final solution, assuming undissolved AzoSM was negligible, contained $1.5 \mathrm{mM}$ AzoSM mixed with $40 \mathrm{mM}$ MaCD.

\section{AzoSM exchange using MaCD and photo- isomerization}

Endogenous sphingomyelin was exchanged for AzoSM using MaCD as previously described $(36,38)$. Briefly, macrophages were seeded as described above and allowed to adhere overnight at $37^{\circ} \mathrm{C}+5 \% \mathrm{CO}_{2}$. Macrophage monolayers were washed twice with 1x Dulbecco's phosphate buffered saline (DPBS). AzoSM-loaded MaCD solution was then added to the cells as follows: 200 $\mu \mathrm{l}$ for 96 -well plates, $1 \mathrm{ml}$ for 6 -well plates, and $2 \mathrm{ml}$ for $100 \mathrm{~mm}$ dishes. Cells were incubated at $37^{\circ} \mathrm{C}+$ $5 \% \mathrm{CO}_{2}$ for 1 hour with gentle shaking.

Macrophage monolayers were then washed four times with 1x DPBS and incubated in serum-free media. To isomerize AzoSM from the dark-adapted trans conformation to the cis conformation, cells were treated with UV light $(\lambda=365 \mathrm{~nm})$ for 20 seconds. To revert the isomerization (from cis conformation back to trans conformation), cells were subsequently treated with blue light $(\lambda=460$ $\mathrm{nm}$ ) for 40 seconds. Cells treated with UV light only subsequently remained in the dark to minimize isomerization back to trans.

In vitro phagocytosis assay

$5 \times 10^{4}$ macrophages were seeded per well in 96-well plates. Cells were allowed to adhere overnight at $37^{\circ} \mathrm{C}+5 \% \mathrm{CO}_{2}$. C. neoformans $\mathrm{H} 99$ cells were grown overnight in YNB at $30^{\circ} \mathrm{C}$ with shaking. Fungal cells were then washed twice with 1x phosphate buffered saline (PBS). For antibodymediated phagocytosis, C. neoformans H99 cells were opsonized for 30 minutes at $37^{\circ} \mathrm{C}+5 \%$ $\mathrm{CO}_{2}$ with shaking using $1 \mu \mathrm{g}$ of antiglucuronoxylomannan (GXM) antibody (39) per $10^{5} \mathrm{C}$. neoformans cells in $100 \mu \mathrm{l}$ of complete media (10\% FBS $+1 \%$ penicillin/streptomycin). Antibodyopsonized $C$. neoformans cells were added to washed macrophage monolayers at a $1: 1$ ratio in $200 \mu \mathrm{l}$ and allowed to interact for 2 hours at $37^{\circ} \mathrm{C}+$ $\begin{array}{llll}5 \% & \mathrm{CO}_{2} & \text { unless noted otherwise. Macrophage }\end{array}$ monolayers were then washed three times with $1 \mathrm{x}$ DPBS to remove extracellular $C$. neoformans, fixed with ice-cold methanol for 15 minutes at room temperature (RT), and stained for 5 minutes at RT with Giemsa (Sigma) diluted 1:1 in deionized water. Stained cells were then washed three times with sterile deionized water and allowed to dry overnight at room temperature. For complement-mediated phagocytosis assays, $C$. neoformans $\mathrm{H} 99$ cells were opsonized for 1 hour at $37^{\circ} \mathrm{C}+5 \% \mathrm{CO}_{2}$ with shaking using $100 \mu \mathrm{l}$ of complement-based media (20\% mouse CD1 complement serum (Innovative Research) in serum-free medium). Complementopsonized $C$. neoformans cells were added to washed macrophage monolayers at a 1:1 ratio with 10 units (1 unit $=0.1 \mathrm{ng} / \mathrm{mL}$ ) of recombinant murine IFN $\gamma$ (Sigma) and $0.3 \mu \mathrm{g} / \mathrm{ml}$ of lipopolysaccharide (Sigma) in $200 \mu \mathrm{l}$ and allowed to interact for 3 hours at $37^{\circ} \mathrm{C}+5 \% \mathrm{CO}_{2}$. Macrophage monolayers were then washed three times with 1x DPBS to remove extracellular $C$. neoformans, fixed with ice-cold 
methanol for 15 minutes at RT, and stained for 5 minutes at RT with Giemsa (Sigma) diluted 1:1 in deionized water. Stained cells were then washed three times with sterile deionized water and allowed to dry overnight at room temperature. Phagocytic index was calculated by microscopic observation. Micrographs were taken of at least 4 independent fields of view per well. At least 200 macrophage cells were counted per well. Ingested $C$. neoformans cells within macrophages were counted. Ingested C. neoformans cells were distinguished from attached cells by the stained macrophage cell membrane surrounding the cryptococcal capsule. Phagocytic index is defined as the percentage of yeast cells ingested per macrophages counted per well (9).

\section{Lipid analysis}

Sphingomyelin and ceramide species were analyzed as previously described (75). 1 × $10^{6}$ macrophages were seeded per well in 6-well plates. Cells were allowed to adhere overnight at $37^{\circ} \mathrm{C}+5 \%$ $\mathrm{CO}_{2}$. Macrophage monolayers were washed twice with 1x DPBS and treated for sphingomyelin depletion as described above. Following treatment, cells were washed three times with $1 \times$ DPBS and subsequently scraped in $1 \mathrm{ml}$ ice-cold 1x DPBS. 10 $\mu \mathrm{l}$ of cell suspension was set aside for protein quantification using the Bradford method. Remaining cells were pelleted at $1,000 \times \mathrm{g}$ for 5 minutes at $4^{\circ} \mathrm{C}$. Lipids were extracted from each cell pellet in $2 \mathrm{ml}$ isopropanol:water:ethyl acetate (30:10:60 by volume). Cell extracts were analyzed by reverse phase high pressure liquid chromatography coupled to electrospray ionization and subsequent separation by mass spectrometry. Analysis of ceramides and sphingomyelins was performed on a TSQ Quantum Ultra mass spectrometer (Thermo Fisher Scientific), operating in a multiple reaction-monitoring positive ionization mode. Sphingolipid levels were normalized to the protein concentration estimated in the original cell extract. All experiments were performed in triplicates.

For analysis of sterols, $1 \times 10^{6}$ macrophages were seeded per well in 6 -well plates. Cells were allowed to adhere overnight at $37^{\circ} \mathrm{C}+5 \% \mathrm{CO}_{2}$. Macrophage monolayers were rinsed twice with $1 \mathrm{x}$ DPBS and treated for cholesterol depletion or sterol substitution as described above. Following treatment, cells were washed three times with $1 \mathrm{x}$ DPBS and subsequently scraped in $1 \mathrm{ml}$ ice-cold $1 \mathrm{x}$ DPBS. $10 \mu \mathrm{l}$ of cell suspension was set aside for protein quantification using the Bradford method. Remaining cells were pelleted at $1,000 \times \mathrm{g}$ for 5 minutes at $4^{\circ} \mathrm{C}$. Sterol derivatization, detection and analysis were performed by gas chromatographymass spectrometry (GC-MS) as previously described $(33,76)$. Briefly, lipids were first extracted in $2 \mathrm{ml}$ isopropanol:water:ethyl acetate (30:10:60 by volume), then subjected to mild alkaline base hydrolysis (0.6 M KOH in methanol) to remove the glycerol backbone containing lipid contaminants $(75,77)$. The extracted and base hydrolyzed lipid samples were derivatized using $100 \mu \mathrm{l}$ BSTFA/TMCS (N,O-bis (trimethylsilyl) trifluoroacetamide/TMCS (trimethylchlorosilane)) reagent at $85^{\circ} \mathrm{C}$ for $90 \mathrm{~min}$. Next, $50 \mu \mathrm{l}$-hexane was added to the derivatized sample and vortexed. The samples were then analyzed using 30 meter $(0.25$ um) DB5-MS column on Agilent 7890 GC-MS (Agilent Technologies). The initial column temperature of $10^{\circ} \mathrm{C}$ was held for $0.5 \mathrm{~min}$, ramped up at $35^{\circ} \mathrm{C} / \mathrm{min}$ to $240^{\circ} \mathrm{C}$, then at $3^{\circ} \mathrm{C} / \mathrm{min}$ to $260^{\circ} \mathrm{C}$, and then at $1.5^{\circ} \mathrm{C} / \mathrm{min}$ to $305^{\circ} \mathrm{C}$ with hold of $2 \mathrm{~min}$. All El-mass spectra were recorded at $70 \mathrm{eV}$ with ion source temperature of $230^{\circ} \mathrm{C}$. Front inlet temperature was kept at $290^{\circ} \mathrm{C}$ and MSD transfer line temperature was kept at $280^{\circ} \mathrm{C}$. The retention time and mass spectral patterns of the appropriate sterol standards were used as a reference. Ergosterol $(25 \mu \mathrm{g})$, a non-mammalian sterol, was added as an internal standard for these analyses prior to lipid extraction. Sterol species contents in each sample were quantified using standard calibration curves and normalized to protein concentration estimated in the original cell extract. All experiments were performed in triplicates.

For AzoSM analysis, $1 \times 10^{6}$ macrophages were seeded per well in 6 -well plates. Cells were allowed to adhere overnight at $37^{\circ} \mathrm{C}+5 \% \mathrm{CO}_{2}$. Macrophage monolayers were rinsed twice with $1 \mathrm{x}$ DPBS and treated for AzoSM exchange as described above. Following treatment, cells were washed four times with 1x DPBS and subsequently scraped in $1 \mathrm{ml}$ ice-cold 1x DPBS. $10 \mu \mathrm{l}$ of cell suspension was set aside for protein quantification using the Bradford method. Remaining cells were evenly split into two tubes and pelleted at $1,000 \times \mathrm{g}$ for 5 minutes at $4^{\circ} \mathrm{C}$. One tube was set aside for sphingomyelin analysis as described above. For AzoSM analysis, cellular lipids were extracted from the second tube for each sample in $1.5 \mathrm{ml}$ Mandala extraction buffer (78), followed by Bligh and Dyer extraction (79), and base hydrolysis (77). Cell extracts were each resuspended in $50 \mu$ methanol and $10 \mu \mathrm{l}$ applied to high-performance liquid chromatograph (HPLC) (Agilent Technologies). AzoSM was detected at $365 \mathrm{~nm}$ on a C-8 column with a flow rate of $0.5 \mathrm{ml} / \mathrm{min}$ in methanol/water 90:10 ratio buffered with $1 \mathrm{mM}$ ammonium formate 
and $0.2 \%$ formic acid (Figure S8). Total AzoSM was calculated for each sample, then normalized to the protein concentration estimated in the original cell extract. All experiments were performed in triplicates.

\section{Förster resonance energy transfer (FRET)}

Biological membrane nanodomain stability was assessed by measuring the temperature dependence of FRET using giant plasma membrane vesicles (GPMVs) as previously described (36). 1.5 $\times 10^{7}$ macrophages were seeded in $100 \mathrm{~mm}$ dishes. Cells were allowed to adhere overnight at $37^{\circ} \mathrm{C}+5 \%$ $\mathrm{CO}_{2}$. Macrophage monolayers were rinsed twice with 1x DPBS and treated for cholesterol depletion or sterol substitution as described above. Following treatment, GPMVs were prepared using as previously described by Sezgin et al. (80) and Levental and Levental (80,81). Briefly, paraformaldehyde (PFA) and dithiothreitol (DTT) were freshly added to the GPMV buffer $(10 \mathrm{mM}$ HEPES, $\left.150 \mathrm{mM} \mathrm{NaCl}, 2 \mathrm{mM} \mathrm{CaCl}_{2}, \mathrm{pH} 7.4\right)$ at a final concentration of $24 \mathrm{mM}$ PFA and $2 \mathrm{mM}$ DTT when desired. Following cholesterol depletion or sterol substitution, macrophage monolayers were washed twice with $1 \times$ DPBS then twice with GPMV buffer lacking PFA and DTT. Next, $2.5 \mathrm{ml}$ of GPMV buffer with PFA and DTT was added and incubated at $37^{\circ} \mathrm{C}+5 \% \mathrm{CO}_{2}$ with gentle shaking. The GPMVcontaining buffer solution was gently harvested by pipetting. To remove intact cells, the solution was centrifuged at $100 \times \mathrm{g}$ for 5 minutes at RT. This GPMV-containing buffer solution was used for the FRET measurements. FRET measurements were made with diphenylhexatriene (DPH) (Sigma) as the FRET donor and Octadecyl Rhodamine B (ODRB) (Invitrogen) as the FRET acceptor. The "F sample" with FRET acceptor was prepared by adding $3.6 \mu \mathrm{l}$ from $1.4 \mathrm{mM}$ ODRB dissolved in ethanol to $1 \mathrm{ml}$ of GPMVs, vortexed, and incubated at $37^{\circ} \mathrm{C}$ for 1 hour in the dark. The " $F_{\circ}$ sample" lacking FRET acceptor was also incubated at $37^{\circ} \mathrm{C}$ for 1 hour with $3.6 \mu \mathrm{l}$ ethanol. Before fluorescence measurements, DPH $(1.2 \mu \mathrm{l}$ from a $5 \mu \mathrm{M}$ stock solution in ethanol) was added to both the "F sample" and "Fo sample" and incubated at room temperature for $5 \mathrm{~min}$ in the dark. Background fluorescence before adding DPH was negligible $(<1 \%$ of samples containing DPH). To initiate measurements, samples were placed in a cuvette and transferred to a temperature-controlled sample spectrofluorometer (Horiba PTI Quantamaster) sample holder and cooled to $16^{\circ} \mathrm{C}$. $\mathrm{DPH}$ fluorescence (excitation $\lambda=358 \mathrm{~nm}$, emission $\lambda=430 \mathrm{~nm}$ ) was measured. Temperature was increased at $4^{\circ} \mathrm{C}$ intervals every 5 minutes up to $64^{\circ} \mathrm{C}$. The ratio of $\mathrm{DPH}$ fluorescence intensity in the presence of ODRB to that in its absence $\left(F / F_{0}\right)$ was then calculated. All $F / F_{0}$ values were normalized to the $F / F_{0}$ value measured at $64^{\circ} \mathrm{C}$. $T_{\text {end }}$, the temperature above which segregation of lipids into ordered and disordered domains was fully lost (i.e., complete "melting" of ordered domains) was estimated by finding the minimum value of a polynomial fit applied to the $F / F_{0}$ as previously described (36). Presence of detectable nanodomains between $16^{\circ} \mathrm{C}$ and $T_{\text {end }}$ was estimated by calculating the area between the polynomial fit and a horizontal line defined by $T_{\text {end }}$ (i.e. $y=y$ value at $x=T_{\text {end }}$ for polynomial fit). All FRET experiments were performed three times.

\section{Flow cytometry}

Flow cytometry was used to assess the presence of Fcy receptors (CD16/CD32) and complement receptor (CD11b) on the cell surface following lipid-altering treatments. $1 \times 10^{6}$ macrophages were seeded per well in 6-well plates. Cells were allowed to adhere overnight at $37^{\circ} \mathrm{C}+5 \%$ $\mathrm{CO}_{2}$. Macrophage monolayers were rinsed twice with $1 \mathrm{x}$ DPBS and treated for cholesterol or sphingomyelin depletion as described above. Following treatment, cells were washed three times with 1x DPBS and subsequently scraped in $1 \mathrm{ml}$ icecold $1 \times$ DPBS. Cell concentrations were determined using a hemacytometer. $1 \times 10^{6}$ cells were transferred into round-bottom test tubes (Falcon) per experimental sample and compensation control (i.e. unstained, single stained) and washed twice with $1 \mathrm{x}$ PBS $+2 \%$ FBS. Cells were labeled with the following antibodies directly conjugated to the following fluorophores: CD45-PE/Cy7 (clone 30-F11, BioLegend), CD11b-BV510 (clone M1/70, BioLegend), and CD16/CD32-APC (clone 93, Invitrogen). Cells were also stained for viability using Alexa Fluor 700 carboxylic acid, succinimidyl ester (Thermo Fisher Scientific). Additional details for the antibodies/markers are available in Table S2. Cells were first incubated with CD16/CD32-APC at $4^{\circ} \mathrm{C}$ for 30 minutes in the dark, then incubated with $C D 11 \mathrm{~b}$ BV510, CD45-PE/Cy7, and the viability stain at $4^{\circ} \mathrm{C}$ for 30 minutes in the dark. All labeling was performed with shaking. Cells were then washed twice with $1 x$ PBS $+2 \%$ FBS and fixed with Fluorofix Buffer (BioLegend) at RT for 30 minutes in the dark with shaking. Cells were washed once and resuspended in $400 \mu \mathrm{l} 1 \mathrm{x}$ PBS $+2 \%$ FBS for analysis. Labeled cell suspensions were analyzed using the CytoFLEX Flow Cytometer (BeckmanCoulter) and FlowJo Software Version 10.6.2 to measure the median fluorescence intensity of CD16/CD32-APC, CD11b-BV510, and CD45- 
PE/Cy7 for 50,000 live CD45 ${ }^{+}$cells. All experiments were performed in triplicates.

\section{Fcy receptor stimulation using $\lg G$ immune complexes}

To assess activation of the Fcy receptor signaling cascade, macrophages were stimulated with BSA-IgG immune complexes (IgGIC) $(59,82)$. Briefly, IgGIC was prepared by incubating $500 \mu \mathrm{g}$ of anti-BSA IgG (MP Biomedicals) per $100 \mu \mathrm{g}$ of BSA (fatty acid-free, protease-free, Sigma) in 100 $\mu \mathrm{l} 1 \mathrm{x}$ PBS at RT for 30 minutes with shaking. IgGIC was diluted with complete media to a final concentration of $100 \mu \mathrm{g} / \mathrm{ml}$. $8.6 \times 10^{6}$ macrophages were seeded in $100 \mathrm{~mm}$ dishes. Cells were allowed to adhere overnight at $37^{\circ} \mathrm{C}+5 \% \mathrm{CO}_{2}$.

Macrophage monolayers were rinsed twice with $1 \mathrm{x}$ DPBS and treated for cholesterol depletion, sterol substitution, or sphingomyelin depletion as described above. Following treatment, cells were washed three times with $1 \times$ DPBS and incubated with $2.5 \mathrm{ml} \mathrm{lgGIC}$ at $37^{\circ} \mathrm{C}+5 \% \mathrm{CO}_{2}$ with gentle shaking. Cell were then washed four times with $1 \mathrm{x}$ DPBS before processing for immunoprecipitation and immunoblotting.

\section{Immunoprecipitation and immunoblotting}

Following Fcy receptor stimulation using $\operatorname{lgGIC}, F c$ receptor $\gamma$-subunit (FcR y subunit) was immunoprecipitated and assessed for phosphorylation of tyrosine residues (59). Cells were lysed directly on the $100 \mathrm{~mm}$ dishes using icecold radio-immunoprecipitation assay (RIPA) buffer (Sigma) supplemented with $0.1 \%$ Triton X-100 (Sigma) and Halt Protease and Phosphatase Inhibitor Cocktail (Sodium Fluoride, Sodium Orthovanadate, $\quad \beta$-glycerophosphate, Sodium Pyrophosphate, Aprotinin, Bestatin, E64, Leupeptin) (Thermo Fisher Scientific). Samples were incubated at $4^{\circ} \mathrm{C}$ for 45 minutes with shaking. Samples were then centrifuged at $4^{\circ} \mathrm{C}, 10,000 \mathrm{rpm}$ for 5 minutes and supernatants were transferred to pre-chilled microtubes. Protein concentration of each sample was determined by the Bradford assay. $200 \mu \mathrm{g}$ each lysate was pre-cleared with $20 \mu \mathrm{l}$ of Protein A agarose beads ( $3 \mathrm{mg} / \mathrm{ml}$, Roche) in $200 \mu$ for 1 hour at $4^{\circ} \mathrm{C}$ on a Labquake Rotator (Barnstead Thermolyne). Pre-cleared lysate was diluted to 500 $\mu \mathrm{l}$ with additional lysis buffer and incubated overnight with $40 \mu \mathrm{l}$ Protein A agarose beads and 4 $\mu g$ anti-FcRy-subunit IgG (Millipore Sigma) at $4^{\circ} \mathrm{C}$ on a Labquake Rotator. Beads were then centrifuged at $4^{\circ} \mathrm{C}, 10,000 \mathrm{rpm}$ for 5 minutes and rinsed five times with lysis buffer. Beads were then mixed with $40 \mu \mathrm{l}$ of Laemmli Sample Buffer (BioRad) containing 5\% $\beta$-mercaptoethanol (Sigma) and boiled for 5 minutes at $95^{\circ} \mathrm{C}$. All samples were centrifuged briefly at $14,000 \mathrm{rpm}$ before being loaded onto two SDSpolyacrylamide gel (4\%-15\% gradient gel, BioRad). Precision Plus Protein Kaleidoscope pre-stained protein ladder (BioRad) was loaded along with the samples. After separation by electrophoresis at 100 $\checkmark$ for 60 minutes in Tris-Glycine/SDS buffer, proteins were transferred to Immobilon-PSQ PVDF membrane $(0.2 \mu \mathrm{m}$ pore size, Millipore Sigma) by electrophoresis at $100 \mathrm{~V}$ for 30 minutes in TrisGlycine/Methanol buffer. Nonspecific antibody binding was blocked using $10 \%$ non-fat dried milk (NFDM) or $10 \%$ BSA in $1 \mathrm{x}$ Tris-buffered saline + $0.05 \%$ Tween 20 (1x TBST).

After blocking with NFDM/1x TBST, FcR $y$ subunit was probed with the anti-FcR $y$ subunit IgG (Millipore Sigma) overnight at $4^{\circ} \mathrm{C}$ with gentle shaking. After blocking with BSA/1x TBST, phosphor-tyrosine was probed with the antiphospho-tyrosine MultiMab mix (Cell Signaling) $4^{\circ} \mathrm{C}$ with gentle shaking. After incubation with primary antibody, membranes were washed five times with $1 \mathrm{x}$ TBST. Both membranes were subsequently incubated for 1 hour at RT with the Clean-Blot IP Detection Reagent (HRP, Thermo Scientific). After washing the membrane three times with $1 \mathrm{x}$ TBST, the secondary antibody was detected using SuperSignal West Femto Maximum Sensitivity Substrate (Thermo Scientific). Bands were visualized using ImageQuant LAS 500 (Cytiva). Bands were quantified using ImageJ. Phosphotyrosine bands were normalized by FcR $\mathrm{Y}$ subunit bands. All experiments were performed three times. Additional details for the antibodies are available in Table S2.

\section{Fluorescent lipid labeling}

$$
\text { EGFP-conjugated }
$$

nakanori

(EGFPnakanori), a protein that labels cell surface domains in a sphingomyelin and cholesterol-dependent manner (46), was used to label macrophages. Plasmid containing EGFP-nakanori was transformed into Escherichia coli strain BL21. Expression was induced in LB media containing Isopropyl $\beta$-D-1-thiogalactopyranoside. The EGFPnakanori protein was subsequently extracted and purified using HisTrap columns (Cytiva) and concentrated using an Amicon centrifugal unit.

Macrophages were subjected to either $10 \mathrm{mM}$ $M \beta C D$ or $250 \mathrm{mU} / \mathrm{ml}$ bSMase treatment as 
described above. Live cells were subsequently coincubated with $50 \mu \mathrm{g}$ EGFP-nakanori for 1 hour, fixed with $4 \%$ formaldehyde, and imaged using the Axio Observer D1 Phase Contrast Fluorescence Microscope (Zeiss). Micrographs were captured using the AxioCam MR R3 camera (Zeiss).

\section{Statistical analysis}

For all statistical analysis, GraphPad Prism Version 8 software was used. Data are represented as mean \pm standard error of the mean (SEM). $\alpha$-level (type 1 error) was set at 0.05 . Differences were considered significant when the probability of type 1 error was less than 5\% ( $<<0.05)$. To compare groups, one-way analysis of variance (ANOVA) with Tukey's multiple comparisons post hoc test was used. All $P$ values from multiple comparisons post hoc tests were corrected for multiplicity using the Bonferroni adjustments.

\section{Data availability}

All data are contained within the manuscript.

\section{Supporting information}

This article contains supporting information.

\section{Acknowledgements}

We would like to acknowledge Stony Brook Cancer Center (Biological Mass Spectrometry Shared Resource) for expert assistance with sphingolipid analysis and the technical support provided by the Research Flow Cytometry Laboratory at Stony Brook Medicine. We especially thank Izolda Mileva and Todd Rueb. We acknowledge Arturo Casadevall from Johns Hopkins University (Baltimore, Maryland, USA) for providing the anti-GXM antibody (clone 18B7) used for opsonization of $C$. neoformans and Yasushi Sako from RIKEN BioResource Research Center (Kyoto, Japan) for providing the EGFP-nakanori plasmid used for cell labeling. We would also like to acknowledge the contributions of Chiara Luberto for her insightful discussion and set up of the initial experiments.

\section{Author contributions}

AMB and JKY conceptualized and performed the experiments, collected the data, performed statistical analyses, and wrote the manuscript. GL helped with FRET experiments and AzoSM exchange protocol. JHK helped with the sterol substitution protocol. AS helped with GC-MS. JM and DT synthesized AzoSM. NPS helped with HPLC. TGN helped with Nakanori staining for microscopy. AF, EL, and MDP conceptualized the experiments and discussed the data. All authors edited the manuscript. The order of co-first authors was determined alphabetically by last name.

\section{Funding and additional information.}

This work was supported by NIH grants Al136934, Al116420, and Al125770 to MDP and GM122493 to EL, the Merit Review Grant I01BX002924 from the Veterans Affairs Program to MDP, Department of Defense grant PR190642. MDP is a recipient of the Research Career Scientist (RCS) Award (IK6 BX005386) and a Burroughs Welcome Investigator in Infectious Diseases at the Veterans Administration Medical Center in Northport, NY. The content is solely the responsibility of the authors and does not necessarily represent the official views of the National Institutes of Health.

\section{Conflict of Interest}

MDP is a Co-Founder and Chief Scientific Officer (CSO) of MicroRid Technologies Inc. AMB, JKY, GL, JK, AS, JM, DT, NPS, TGN, AF, and EL declare that they have no conflicts of interest with the contents of this article.

\section{References}

1. Perfect, J. R., and Casadevall, A. (2002) Cryptococcosis. Infect Dis Clin North Am 16, 837-874, v-vi

2. Eisenman, H. C., Casadevall, A., and McClelland, E. E. (2007) New insights on the pathogenesis of invasive Cryptococcus neoformans infection. Curr Infect Dis Rep 9, 457-464

3. Rajasingham, R., Smith, R. M., Park, B. J., Jarvis, J. N., Govender, N. P., Chiller, T. M., Denning, D. W., Loyse, A., and Boulware, D. R. (2017) Global burden of disease of HIV-associated cryptococcal meningitis: an updated analysis. Lancet Infect Dis 17, 873-881

4. Casadevall, A., Coelho, C., and Alanio, A. (2018) Mechanisms of Cryptococcus neoformans-Mediated Host Damage. Front Immunol 9, 855

5. Nelson, B. N., Hawkins, A. N., and Wozniak, K. L. (2020) Pulmonary Macrophage and Dendritic Cell Responses to Cryptococcus neoformans. Front Cell Infect Microbiol 10, 37 
6. Kechichian, T. B., Shea, J., and Del Poeta, M. (2007) Depletion of alveolar macrophages decreases the dissemination of a glucosylceramide-deficient mutant of Cryptococcus neoformans in immunodeficient mice. Infect Immun 75, 4792-4798

7. Casadevall, A. (2010) Cryptococci at the brain gate: break and enter or use a Trojan horse? J Clin Invest 120, 1389-1392

8. Chretien, F., Lortholary, O., Kansau, I., Neuville, S., Gray, F., and Dromer, F. (2002) Pathogenesis of cerebral Cryptococcus neoformans infection after fungemia. $J$ Infect Dis 186, 522-530

9. Luberto, C., Martinez-Marino, B., Taraskiewicz, D., Bolanos, B., Chitano, P., Toffaletti, D. L., Cox, G. M., Perfect, J. R., Hannun, Y. A., Balish, E., and Del Poeta, M. (2003) Identification of App1 as a regulator of phagocytosis and virulence of Cryptococcus neoformans. Journal of Clinical Investigation 112, 1080-1094

10. Ben-Abdallah, M., Sturny-Leclere, A., Ave, P., Louise, A., Moyrand, F., Weih, F., Janbon, G., and Memet, S. (2012) Fungal-induced cell cycle impairment, chromosome instability and apoptosis via differential activation of NF-kappaB. PLoS Pathog 8, e1002555

11. Coelho, C., Souza, A. C., Derengowski Lda, S., de Leon-Rodriguez, C., Wang, B., Leon-Rivera, R., Bocca, A. L., Goncalves, T., and Casadevall, A. (2015) Macrophage mitochondrial and stress response to ingestion of Cryptococcus neoformans. J Immunol 194, 2345-2357

12. Ma, H., Croudace, J. E., Lammas, D. A., and May, R. C. (2006) Expulsion of live pathogenic yeast by macrophages. Curr Biol 16, 2156-2160

13. Alvarez, M., and Casadevall, A. (2007) Cell-to-cell spread and massive vacuole formation after Cryptococcus neoformans infection of murine macrophages. BMC Immuno/ 8, 16

14. Liu, T. B., Perlin, D. S., and Xue, C. Y. (2012) Molecular mechanisms of cryptococcal meningitis. Virulence 3, 173-181

15. McQuiston, T. J., and Williamson, P. R. (2012) Paradoxical roles of alveolar macrophages in the host response to Cryptococcus neoformans. Journal of Infection and Chemotherapy 18, 1-9

16. Garcia-Rodas, R., and Zaragoza, O. (2012) Catch me if you can: phagocytosis and killing avoidance by Cryptococcus neoformans. Fems Immunology and Medical Microbiology 64, 147-161

17. Coelho, C., Bocca, A. L., and Casadevall, A. (2014) The Intracellular Life of Cryptococcus neoformans. Annual Review of Pathology: Mechanisms of Disease, Vol 9 9, 219-238

18. Sarantis, H., and Grinstein, S. (2012) Subversion of phagocytosis for pathogen survival. Cell Host Microbe 12, 419-431

19. Rougerie, P., Miskolci, V., and Cox, D. (2013) Generation of membrane structures during phagocytosis and chemotaxis of macrophages: role and regulation of the actin cytoskeleton. Immunol Rev 256, 222239

20. Rao, M., Peachman, K. K., Alving, C. R., and Rothwell, S. W. (2003) Depletion of cellular cholesterol interferes with intracellular trafficking of liposome-encapsulated ovalbumin. Immunology and Cell Biology 81, 415-423

21. Sein, K. K., and Aikawa, M. (1998) The prime role of plasma membrane cholesterol in the pathogenesis of immune evasion and clinical manifestations of falciparum malaria. Medical Hypotheses 51, 105-110

22. Pucadyil, T. J., Tewary, P., Madhubala, R., and Chattopadhyay, A. (2004) Cholesterol is required for Leishmania donovani infection: implications in leishmaniasis. Molecular and Biochemical Parasitology 133, 145-152

23. Kannan, S., Audet, A., Huang, H., Chen, L. J., and Wu, M. (2008) Cholesterol-rich membrane rafts and Lyn are involved in phagocytosis during Pseudomonas aeruginosa infection. J Immunol 180, 23962408

24. Wang, M., and Hajishengallis, G. (2008) Lipid raft-dependent uptake, signalling and intracellular fate of Porphyromonas gingivalis in mouse macrophages. Cell Microbiol 10, 2029-2042

25. Lee, J.-H., Kim, D. Y., Lee, S. H., Song, D.-K., Bae, J.-H., and Im, S.-S. (2019) LPS-induced mTORC1 Signaling Activates Lipid Raft-Actin Cytoskeletal Interactions for Phagocytosis through SREBP-1a. 33, Ib318-lb318

26. Magenau, A., Benzing, C., Proschogo, N., Don, A. S., Hejazi, L., Karunakaran, D., Jessup, W., and Gaus, K. (2011) Phagocytosis of IgG-coated polystyrene beads by macrophages induces and requires high membrane order. Traffic 12, 1730-1743

27. Schmidt, F., Thywissen, A., Goldmann, M., Cunha, C., Cseresnyes, Z., Schmidt, H., Rafiq, M., Galiani, S., Graler, M. H., Chamilos, G., Lacerda, J. F., Campos, A., Jr., Eggeling, C., Figge, M. T., Heinekamp, 
T., Filler, S. G., Carvalho, A., and Brakhage, A. A. (2020) Flotillin-Dependent Membrane Microdomains Are Required for Functional Phagolysosomes against Fungal Infections. Cell Rep 32, 108017

28. Crane, J. M., and Tamm, L. K. (2004) Role of cholesterol in the formation and nature of lipid rafts in planar and spherical model membranes. Biophysical Journal 86, 2965-2979

29. Brown, D. A., and London, E. (1998) Functions of lipid rafts in biological membranes. Annual Review of Cell and Developmental Biology 14, 111-136

30. Simons, K., and Toomre, D. (2000) Lipid rafts and signal transduction. Nature Reviews Molecular Cell Biology 1, 31-39

31. Rajendran, L., and Simons, K. (2005) Lipid rafts and membrane dynamics. J Cell Sci 118, 1099-1102

32. Li, G. T., Kim, J., Huang, Z., St Clair, J. R., Brown, D. A., and London, E. (2016) Efficient replacement of plasma membrane outer leaflet phospholipids and sphingolipids in cells with exogenous lipids.

Proceedings of the National Academy of Sciences of the United States of America 113, 14025-14030

33. Kim, J., Singh, A., Del Poeta, M., Brown, D. A., and London, E. (2017) The effect of sterol structure upon clathrin-mediated and clathrin-independent endocytosis. Journal of Cell Science 130, 2682-2695

34. Diaz, O., Mebarek-Azzam, S., Benzaria, A., Dubois, M., Lagarde, M., Nemoz, G., and Prigent, A. F. (2005) Disruption of lipid rafts stimulates phospholipase d activity in human lymphocytes: implication in the regulation of immune function. J Immunol 175, 8077-8086

35. Audi, A., Soudani, N., Dbaibo, G., and Zaraket, H. (2020) Depletion of Host and Viral Sphingomyelin Impairs Influenza Virus Infection. Front Microbiol 11, 612

36. Li, G., Wang, Q., Kakuda, S., and London, E. (2020) Nanodomains can persist at physiologic temperature in plasma membrane vesicles and be modulated by altering cell lipids. J Lipid Res 61, 758766

37. Suresh, P., Miller, W. T., and London, E. (2021) Phospholipid exchange shows insulin receptor activity is supported by both the propensity to form wide bilayers and ordered raft domains. Journal of Biological Chemistry 297

38. Bryan, A. M., Farnoud, A. M., Mor, V., and Del Poeta, M. (2014) Macrophage Cholesterol Depletion and Its Effect on the Phagocytosis of Cryptococcus neoformans. Jove-Journal of Visualized Experiments

39. Casadevall, A., Cleare, W., Feldmesser, M., Glatman-Freedman, A., Goldman, D. L., Kozel, T. R., Lendvai, N., Mukherjee, J., Pirofski, L. A., Rivera, J., Rosas, A. L., Scharff, M. D., Valadon, P., Westin, K., and Zhong, Z. J. (1998) Characterization of a murine monoclonal antibody to Cryptococcus neoformans polysaccharide that is a candidate for human therapeutic studies. Antimicrobial Agents and Chemotherapy 42, 1437-1446

40. Canals, D., Jenkins, R. W., Roddy, P., Hernandez-Corbacho, M. J., Obeid, L. M., and Hannun, Y. A. (2010) Differential Effects of Ceramide and Sphingosine 1-Phosphate on ERM Phosphorylation PROBING SPHINGOLIPID SIGNALING AT THE OUTER PLASMA MEMBRANE. Journal of Biological Chemistry 285, 32476-32485

41. Zidovetzki, R., and Levitan, I. (2007) Use of cyclodextrins to manipulate plasma membrane cholesterol content: Evidence, misconceptions and control strategies. Biochimica Et Biophysica ActaBiomembranes 1768, 1311-1324

42. Xu, X., and London, E. (2000) The effect of sterol structure on membrane lipid domains reveals how cholesterol can induce lipid domain formation. Biochemistry 39, 843-849

43. Xu, X., Bittman, R., Duportail, G., Heissler, D., Vilcheze, C., and London, E. (2001) Effect of the structure of natural sterols and sphingolipids on the formation of ordered sphingolipid/sterol domains (rafts). Comparison of cholesterol to plant, fungal, and disease-associated sterols and comparison of sphingomyelin, cerebrosides, and ceramide. J Biol Chem 276, 33540-33546

44. Megha, and London, E. (2004) Ceramide selectively displaces cholesterol from ordered lipid domains (rafts): implications for lipid raft structure and function. J Biol Chem 279, 9997-10004

45. Megha, Bakht, O., and London, E. (2006) Cholesterol precursors stabilize ordinary and ceramide-rich ordered lipid domains (lipid rafts) to different degrees. Implications for the Bloch hypothesis and sterol biosynthesis disorders. J Biol Chem 281, 21903-21913

46. Makino, A., Abe, M., Ishitsuka, R., Murate, M., Kishimoto, T., Sakai, S., Hullin-Matsuda, F., Shimada, Y., Inaba, T., Miyatake, H., Tanaka, H., Kurahashi, A., Pack, C. G., Kasai, R. S., Kubo, S., Schieber, N. L., Dohmae, N., Tochio, N., Hagiwara, K., Sasaki, Y., Aida, Y., Fujimori, F., Kigawa, T., Nishibori, K., Parton, R. G., Kusumi, A., Sako, Y., Anderluh, G., Yamashita, M., Kobayashi, T., Greimel, P., and Kobayashi, T. (2017) A novel sphingomyelin/cholesterol domain-specific probe reveals the dynamics of 
bioRxiv preprint doi: https://doi.org/10.1101/2021.11.02.466923; this version posted November 2, 2021. The copyright holder for this preprint

(which was not certified by peer review) is the author/funder. All rights reserved. No reuse allowed without permission.

the membrane domains during virus release and in Niemann- Pick type C. Faseb Journal 31, 13011322

47. Morstein, J., Impastato, A. C., and Trauner, D. (2021) Photoswitchable Lipids. Chembiochem 22, 73-83

48. Doroudgar, M., Morstein, J., Becker-Baldus, J., Trauner, D., and Glaubitz, C. (2021) How

Photoswitchable Lipids Affect the Order and Dynamics of Lipid Bilayers and Embedded Proteins. J Am Chem Soc

49. Frank, J. A., Franquelim, H. G., Schwille, P., and Trauner, D. (2016) Optical Control of Lipid Rafts with Photoswitchable Ceramides. Journal of the American Chemical Society 138, 12981-12986

50. Kol, M., Williams, B., Toombs-Ruane, H., Franquelim, H. G., Korneev, S., Schroeer, C., Schwille, P., Trauner, D., Holthuis, J. C., and Frank, J. A. (2019) Optical manipulation of sphingolipid biosynthesis using photoswitchable ceramides. Elife 8

51. Morstein, J., Hill, R. Z., Novak, A. J. E., Feng, S., Norman, D. D., Donthamsetti, P. C., Frank, J. A., Harayama, T., Williams, B. M., Parrill, A. L., Tigyi, G. J., Riezman, H., Isacoff, E. Y., Bautista, D. M., and Trauner, D. (2019) Optical control of sphingosine-1-phosphate formation and function. Nat Chem Biol 15, 623-631

52. Morstein, J., Kol, M., Novak, A. J. E., Feng, S., Khayyo, S., Hinnah, K., Li-Purcell, N., Pan, G., Williams, B. M., Riezman, H., Atilla-Gokcumen, G. E., Holthuis, J. C. M., and Trauner, D. (2021) Short Photoswitchable Ceramides Enable Optical Control of Apoptosis. ACS Chem Biol 16, 452-456

53. Hartrampf, N., Seki, T., Baumann, A., Watson, P., Vepřek, N. A., Hetzler, B. E., Hoffmann-Röder, A., Tsuji, M., and Trauner, D. (2020) Optical Control of Cytokine Production Using Photoswitchable Galactosylceramides. Chemistry 26, 4476-4479

54. Morstein, J., Awale, M., Reymond, J.-L., and Trauner, D. (2019) Mapping the Azolog Space Enables the Optical Control of New Biological Targets. ACS Central Science 5, 607-618

55. Hartrampf, N., Leitao, S. M., Winter, N., Toombs-Ruane, H., Frank, J. A., Schwille, P., Trauner, D., and Franquelim, H. G. (2021) Structural Diversity of Photoswitchable Sphingolipids for Optodynamic Control of Lipid Raft Microdomains. bioRxiv, 2021.2010.2011.463883

56. Frank, J. A., Franquelim, H. G., Schwille, P., and Trauner, D. (2016) Optical Control of Lipid Rafts with Photoswitchable Ceramides. J Am Chem Soc 138, 12981-12986

57. Bruhns, P. (2012) Properties of mouse and human IgG receptors and their contribution to disease models. Blood 119, 5640-5649

58. Cross, C. E., Collins, H. L., and Bancroft, G. J. (1997) CR3-dependent phagocytosis by murine macrophages: Different cytokines regulate ingestion of a defined CR3 ligand and complementopsonized Cryptococcus neoformans. Immunology 91, 289-296

59. Rittirsch, D., Flierl, M. A., Day, D. E., Nadeau, B. A., Zetoune, F. S., Sarma, J. V., Werner, C. M., Wanner, G. A., Simmen, H. P., Huber-Lang, M. S., and Ward, P. A. (2009) Cross-talk between TLR4 and FcgammaReceptorllI (CD16) pathways. PLoS Pathog 5, e1000464

60. Yuan, R., Clynes, R., Oh, J., Ravetch, J. V., and Scharff, M. D. (1998) Antibody-mediated modulation of Cryptococcus neoformans infection is dependent on distinct Fc receptor functions and IgG subclasses. J Exp Med 187, 641-648

61. Kara, S., Amon, L., Luhr, J. J., Nimmerjahn, F., Dudziak, D., and Lux, A. (2020) Impact of Plasma Membrane Domains on IgG Fc Receptor Function. Front Immunol 11, 1320

62. Kondadasula, S. V., Roda, J. M., Parihar, R., Yu, J., Lehman, A., Caligiuri, M. A., Tridandapani, S., Burry, R. W., and Carson, W. E., 3rd. (2008) Colocalization of the IL-12 receptor and FcgammaRIIIa to natural killer cell lipid rafts leads to activation of ERK and enhanced production of interferon-gamma. Blood 111, 4173-4183

63. Galandrini, R., Tassi, I., Mattia, G., Lenti, L., Piccoli, M., Frati, L., and Santoni, A. (2002) SH2containing inositol phosphatase (SHIP-1) transiently translocates to raft domains and modulates CD16mediated cytotoxicity in human NK cells. Blood 100, 4581-4589

64. St Clair, J. W., and London, E. (2019) Effect of sterol structure on ordered membrane domain (raft) stability in symmetric and asymmetric vesicles. Biochim Biophys Acta Biomembr 1861, 1112-1122

65. Delle Bovi, R. J., Kim, J., Suresh, P., London, E., and Miller, W. T. (2019) Sterol structure dependence of insulin receptor and insulin-like growth factor 1 receptor activation. Biochim Biophys Acta Biomembr 1861, 819-826

66. Varshney, P., Yadav, V., and Saini, N. (2016) Lipid rafts in immune signalling: current progress and future perspective. Immunology 149, 13-24 
67. Turner, H., and Kinet, J.-P. (1999) Signalling through the high-affinity IgE receptor FceRI. Nature 402, 24-30

68. Slotte, J. P., Hedstrom, G., Rannstrom, S., and Ekman, S. (1989) Effects of sphingomyelin degradation on cell cholesterol oxidizability and steady-state distribution between the cell surface and the cell interior. Biochim Biophys Acta 985, 90-96

69. Ridgway, N. D., Lagace, T. A., Cook, H. W., and Byers, D. M. (1998) Differential effects of sphingomyelin hydrolysis and cholesterol transport on oxysterol-binding protein phosphorylation and Golgi localization. J Biol Chem 273, 31621-31628

70. Grassme, H., Jendrossek, V., Riehle, A., von Kurthy, G., Berger, J., Schwarz, H., Weller, M., Kolesnick, R., and Gulbins, E. (2003) Host defense against Pseudomonas aeruginosa requires ceramide-rich membrane rafts. Nat Med 9, 322-330

71. Grassme, H., Schwarz, H., and Gulbins, E. (2001) Molecular mechanisms of ceramide-mediated CD95 clustering. Biochem Biophys Res Commun 284, 1016-1030

72. Suchard, S. J., Hinkovska-Galcheva, V., Mansfield, P. J., Boxer, L. A., and Shayman, J. A. (1997) Ceramide inhibits IgG-dependent phagocytosis in human polymorphonuclear leukocytes. Blood 89, 2139-2147

73. Abdel Shakor, A. B., Kwiatkowska, K., and Sobota, A. (2004) Cell surface ceramide generation precedes and controls FcgammaRII clustering and phosphorylation in rafts. J Biol Chem 279, 3677836787

74. Ravetch, J. V., and Lanier, L. L. (2000) Immune inhibitory receptors. Science 290, 84-89

75. Bielawski, J., Pierce, J. S., Snider, J., Rembiesa, B., Szulc, Z. M., and Bielawska, A. (2010) Sphingolipid Analysis by High Performance Liquid Chromatography-Tandem Mass Spectrometry (HPLC-MS/MS). Sphingolipids as Signaling and Regulatory Molecules 688, 46-59

76. Singh, A., MacKenzie, A., Girnun, G., and Del Poeta, M. (2017) Analysis of sphingolipids, sterols, and phospholipids in human pathogenic Cryptococcus strains. Journal of Lipid Research 58, 2017-2036

77. Clarke, N. G., and Dawson, R. M. (1981) Alkaline O leads to N-transacylation. A new method for the quantitative deacylation of phospholipids. Biochem J 195, 301-306

78. Mandala, S. M., Thornton, R. A., Frommer, B. R., Curotto, J. E., Rozdilsky, W., Kurtz, M. B., Giacobbe, R. A., Bills, G. F., Cabello, M. A., Martin, I., and et al. (1995) The discovery of australifungin, a novel inhibitor of sphinganine $\mathrm{N}$-acyltransferase from Sporormiella australis. Producing organism, fermentation, isolation, and biological activity. J Antibiot (Tokyo) 48, 349-356

79. Bligh, E. G., and Dyer, W. J. (1959) A rapid method of total lipid extraction and purification. Can J Biochem Physiol 37, 911-917

80. Sezgin, E., Kaiser, H. J., Baumgart, T., Schwille, P., Simons, K., and Levental, I. (2012) Elucidating membrane structure and protein behavior using giant plasma membrane vesicles. Nat Protoc 7, 10421051

81. Levental, K. R., and Levental, I. (2015) Isolation of giant plasma membrane vesicles for evaluation of plasma membrane structure and protein partitioning. Methods Mol Biol 1232, 65-77

82. Sun, L., Guo, R. F., Gao, H., Sarma, J. V., Zetoune, F. S., and Ward, P. A. (2009) Attenuation of IgG immune complex-induced acute lung injury by silencing $\mathrm{C} 5 \mathrm{aR}$ in lung epithelial cells. FASEB J 23, 3808-3818

Abbreviations: bacterial sphingomyelinase (bSMase); BSA-IgG immune complexes (IgGICs); Fc receptor $\gamma$ subunit (FcRY); Fcy receptor (FcyR); Fcع receptor I (FcعRI); Förster resonance energy transfer (FRET); giant plasma membrane vesicles (GPMVs); glucuronoxylomannan (GXM); immunoreceptor tyrosine-based activation motif (ITAM); immunoreceptor tyrosine-based inhibitory motif (ITIM); methyl-beta-cyclodextrin $(\mathrm{M} \beta C D)$.

Table S1. Nanodomain characteristics for GPMVs after cholesterol depletion or sterol repletion

\begin{tabular}{|l|c|c|}
\hline \multicolumn{1}{|c|}{ Treatment condition } & $T_{\text {end }}\left({ }^{\circ} \mathrm{C}\right)$ & $\begin{array}{c}\text { Relative nanodomain } \\
\text { formation (area) }\end{array}$ \\
\hline Untreated control & $50.6 \pm 0.7$ & $18.1 \pm 1.1$ \\
\hline
\end{tabular}




\begin{tabular}{|c|c|c|}
\hline Depletion: $10 \mathrm{mM} \mathrm{M} \beta C D$ & $45.1 \pm 0.8$ & $9.6 \pm 1.3$ \\
\hline Depletion: 30 mM M $\beta C D$ & $39.8 \pm 6.4$ & $2.2 \pm 1.1$ \\
\hline Repletion: $0.2 \mathrm{mM}$ cholesterol/2.5 mM MßCD & $52.3 \pm 1.6$ & $28.0 \pm 3.7$ \\
\hline $\begin{array}{l}\text { Repletion: } 0.2 \text { mM 7-dehydrocholesterol/2.5 } \\
\text { mM MßCD }\end{array}$ & $56.2 \pm 1.7$ & $42.2 \pm 2.2$ \\
\hline Repletion: $0.2 \mathrm{mM}$ coprostanol/2.5 mM MßCD & $41.3 \pm 0.9$ & $2.7 \pm 0.5$ \\
\hline $250 \mathrm{mU} / \mathrm{ml}$ bSMase treatment & $54.9 \pm 1.7$ & $17.6 \pm 1.9$ \\
\hline $500 \mathrm{mU} / \mathrm{ml}$ bSMase treatment & $52.2 \pm 2.0$ & $14.6 \pm 3.5$ \\
\hline
\end{tabular}

Mean and standard error of the mean (SEM) values from three experiments are shown, except for untreated controls $(n=9)$ and depletion with $10 \mathrm{mM} \mathrm{M \beta CD}(n=6)$.

Table S2. Antibodies/markers used in this study

\begin{tabular}{|l|l|l|l|l|}
\hline Catalog number & Manufacturer & Name & Final dilution & Experiment \\
\hline 103114 & BioLegend & CD45-PE/Cy7 & $1: 800$ & Flow cytometry \\
\hline 101263 & BioLegend & CD11b-BV510 & $1: 500$ & Flow cytometry \\
\hline A20110 & Invitrogen & CD16/32-APC & $1: 800$ & Flow cytometry \\
\hline $06-727$ & Invitrogen & $\begin{array}{l}\text { Alex Fluor 700, } \\
\text { carboxylic acid, } \\
\text { succinimidyl ester }\end{array}$ & $1: 1200$ & Flow cytometry \\
\hline $8954 S$ & Sigma-Aldrich & $\begin{array}{l}\text { anti-FcERI, Y } \\
\text { subunit }\end{array}$ & $1: 1000$ & Western blot \\
\hline 21230 & Technology & $\begin{array}{l}\text { Phospho-Tyrosine } \\
\text { (P-Tyr-1000) } \\
\text { MultiMab } \\
\text { mAb } \text { Rabbit }\end{array}$ & $1: 3000$ & Western blot \\
\hline
\end{tabular}

\section{Figure legends}

Figure 1. Cholesterol and sphingomyelin are important for antibody-mediated phagocytosis.

A) Macrophages (MH-S) treated with either 10 or $30 \mathrm{mM}$ methyl-beta-cyclodextrin (MßCD) were co-incubated with antibody-opsonized $C$. neoformans $\mathrm{H} 99$ at a 1:1 ratio and allowed to interact for 2 hours. Cells were then fixed and stained with Giemsa and phagocytic index was calculated by microscopic observation $(n=4)$. B) Macrophages (MH-S) treated with either 250 or $500 \mathrm{mU} / \mathrm{ml}$ bacterial sphingomyelinase (bSMase) were coincubated with antibody-opsonized $C$. neoformans $\mathrm{H} 99$ at a 1:1 ratio and allowed to interact for 2 hours. Cells were then fixed and stained with Giemsa and phagocytic index was calculated by microscopic observation ( $\mathrm{n=3}$ ). C) Macrophages (MH-S) treated with $30 \mathrm{mM} \mathrm{M \beta CD}$ or $500 \mathrm{mU} / \mathrm{ml}$ bSMase were co-incubated with complement serum-opsonized $C$. neoformans $\mathrm{H} 99$ at a 1:1 ratio and allowed to interact for 3 hours. Cells were then fixed and stained with Giemsa and phagocytic index was calculated by microscopic observation $(n=4)$. 
Error bars represent the standard error of the mean (SEM), and statistical significance was determined using one-way ANOVA with Tukey's multiple comparisons test. ${ }^{*} P<0.05$, ${ }^{* *} P<0.001$ compared to the untreated control. All $P$-values were adjusted for multiplicity.

Figure 2. Measurement of sphingolipids after treatment with bacterial sphingomyelinase. Macrophages (J774.1) were treated with either 250 or $500 \mathrm{mU} / \mathrm{ml}$ bacterial sphingomyelinase (bSMase). Monolayers were then washed and subject to lipid extraction. Lipid extracts were then analyzed using liquid chromatography coupled mass spectrometry and normalized to protein found in the cell extract using the Bradford assay. A) Sphingomyelin (SM) species in the treated samples are shown $(n=3)$. B) Ceramide (Cer) species in the treated samples are shown $(n=3)$. Error bars represent the SEM and statistical significance was determined using ANOVA with Tukey's multiple comparisons test. Not significant (ns), ${ }^{\star} P<0.05$, ${ }^{\star \star} P<0.01$, ${ }^{\star \star \star} P<0.005$, ${ }^{* \star \star \star} P$ $<0.0001$ compared to the untreated control. All $P$-values were adjusted for multiplicity.

Figure 3. Repletion with raft altering sterols affects phagocytosis. A) Macrophages (J774.1) were pretreated with $10 \mathrm{mM} \mathrm{M \beta CD}$ to deplete cholesterol and then washed and incubated with $2.5 \mathrm{mM}$ M $\beta C D$ loaded with $0.2 \mathrm{mM}$ of indicated sterol. Monolayers were then washed and subject to lipid extraction. Lipid extracts were then analyzed using gas chromatography coupled mass spectrometry and normalized to protein found in the cell extract by the Bradford assay $(n=3)$. B) Macrophages were pre-treated with $10 \mathrm{mM} \mathrm{M \beta CD}$ to deplete cholesterol and then washed and incubated with $2.5 \mathrm{mM} \mathrm{M \beta CD}$ loaded with $0.2 \mathrm{mM}$ of indicated sterol.

Monolayers were then washed and allowed to interact with antibody opsonized C. neoformans H99 at a 1:1 ratio for 2 hours. Cells were then fixed and stained with Giemsa and phagocytic index was calculated by microscopic observation ( $n=3)$. Error bars represent SEM and statistical significance was determined using one-way ANOVA with Tukey's multiple comparisons test. Not significant (ns), ${ }^{*} P<0.05$, ${ }^{* *} P<0.01$, ${ }^{* * *} P<$ 0.0001 compared to the cellular cholesterol for untreated control. ${ }^{\star} P<0.05$ compared to the cellular 7 dehydrocholesterol for untreated control. ${ }^{u 4} P<0.01$ compared to the cellular coprostanol for untreated control. All $P$-values were adjusted for multiplicity.

Figure 4. Repletion with raft altering sterols affects nanodomain stability. A) Macrophages (MH-S) were pre-treated with either 10 or $30 \mathrm{mM} \mathrm{M \beta CD}$ to deplete cholesterol. Monolayers were then washed and subject to giant plasma membrane vesicle formation using $25 \mathrm{mM}$ PFA and $2 \mathrm{mM}$ DTT. Nanodomain stability was assessed via FRET with DPH as the FRET donor and ODRB as the FRET acceptor. The ratio of DPH fluorescence intensity in the presence vs. absence of ODRB was calculated $\left(F / F_{0}\right)$. $F / F_{0}$ values were normalized to the final $F / F_{0}$ value at $64^{\circ} \mathrm{C}(n=3)$. B) Macrophages were pre-treated with $10 \mathrm{mM} M \beta C D$ to deplete cholesterol and then washed and incubated with $2.5 \mathrm{mM} \mathrm{M \beta CD}$ loaded with $0.2 \mathrm{mM}$ of indicated sterol. Monolayers were then washed and subject to giant plasma membrane vesicle formation using 25 mM PFA and $2 \mathrm{mM}$ DTT. Nanodomain stability was assessed via FRET with DPH as the FRET donor and ODRB as the FRET acceptor. The ratio of DPH fluorescence intensity in the presence vs. absence of ODRB was calculated $\left(F / F_{0}\right) . F / F_{0}$ values were normalized to the final $F / F_{0}$ value at $64^{\circ} \mathrm{C}(n=3)$. C) Relative domain levels were estimated using the polynomial fits from A \& B as described under Experimental procedures. Error bars represent SEM. Detectable nanodomains were compared using one-way ANOVA with Tukey's multiple comparisons test. ${ }^{* *} P<0.01,{ }^{* * * *} P<0.0001$ compared to the untreated control, ${ }^{\# \# \#} P<0.0001$ compared to 10 $\mathrm{mM} \mathrm{M \beta CD},{ }^{\wedge \wedge \wedge \wedge P} P<0.0001,{ }^{\star \star \star} P<0.001,{ }^{\star \star \star \star} P<0.0001$ compared to $0.2 \mathrm{mM}$ cholesterol, and ${ }^{\star \bullet \bullet} P<$ 0.0001 compared to $0.2 \mathrm{mM}$ coprostanol. All $P$-values were adjusted for multiplicity.

Figure 5. Nakanori labeling is affected by lipid altering treatments. Macrophages (MH-S) were adhered onto glass bottomed microscopy dishes. After treatment with $10 \mathrm{mM} \mathrm{M \beta CD}$ or $250 \mathrm{mU} / \mathrm{ml}$ bacterial sphingomyelinase (bSMase) as described under Experimental Procedures, live macrophages were labeled with recombinant nakanori-EGFP and then fixed with $4 \%$ paraformaldehyde. Scale bar=10 $\mu \mathrm{m}$. 
Figure 6. Exclusion of sphingomyelin from rafts affects phagocytosis $C$. neoformans. A) Macrophages (MH-S) treated with the AzoSM exchange protocol using MaCD as described in Experimental Procedures. Cell extracts were then evaluated for endogenous C16 sphingomyelin (C16 SM) using LC-MS and AzoSM using HPLC. Lipid content from each sample was normalized by protein content as determined using the Bradford assay $(n=3)$ B) Macrophages (MH-S) treated with the AzoSM exchange protocol were either unexposed, exposed to UV light, or exposed to UV light followed by blue light. Control samples were mock treated. Washed monolayers were then co-incubated at a 1:1 ratio with C. neoformans H99 opsonized with 18B7 antibody and allowed to interact for 30 minutes. Cells were then fixed and stained with Giemsa and phagocytic index was calculated by microscopic observation. Error bars represent the standard error of the mean and statistical significance was determined using two-way analysis of variance with Tukey's multiple comparisons test $(\mathrm{n}=4) .{ }^{*} P<0.05,{ }^{* *} P<0.01$, and ${ }^{* * *} P<0.0001$. All $P$-values were adjusted for multiplicity.

Figure 7. Lipid depleting treatments affect Fcy receptor-mediated signaling. A) Macrophages (MH-S) were mock-treated (control) or treated with bSMase and subsequently stimulated with BSA-lgG immune complex (IC) for $5 \mathrm{~min}$. Fc receptor $\mathrm{Y}$ chain (FcRY) was immunoprecipitated (IP) and evaluated for phosphorylation of the tyrosine residues. IP samples were probed for FcRy or phospho-tyrosine ( $p$-Tyr). Representative immunoblots are shown. B) Immunoblots were quantified using ImageJ software; $p$-Tyr was normalized by FcRy ( $n=3$ experiments). Error bars represent the standard error of the mean (SEM), and statistical significance was determined using one-way ANOVA with Tukey's multiple comparisons test. ${ }^{*} P<$ 0.05. All $P$-values were adjusted for multiplicity using Bonferroni's correction. $\mathbf{C}) \mathrm{MH}$-S cells were mock-treated (control) or treated with M $\mathrm{BCD}$ and subsequently stimulated with BSA-IgG IC for 5 min. FcRy was IP and evaluated for phosphorylation of the tyrosine residue. IP samples were probed for FcRY or p-Tyr.

Representative immunoblots are shown. D) Immunoblots were quantified using ImageJ software; $p$-Tyr was normalized by FcRY $(n=3)$. Error bars represent the SEM and statistical significance was determined using one-way analysis of variance with Tukey's multiple comparisons test compared to the control. ${ }^{*} P<0.05$. All $P$ values were adjusted for multiplicity.

Figure 8. Repletion with raft-altering sterols affects Fcy receptor-mediated signaling. A) Macrophages were mock-treated (control) or pre-treated with $10 \mathrm{mM} \mathrm{M \beta CD}$ to deplete cholesterol and then washed and incubated with $2.5 \mathrm{mM} \mathrm{M \beta CD}$ loaded with $0.2 \mathrm{mM}$ of indicated sterol. Cells were then stimulated with BSA-IgG immune complex (IC) for 5 min. Fc receptor y chain (FcRY) was immunoprecipitated and evaluated for phosphorylation of the tyrosine residue. IP samples were probed for FcRy or phospho-tyrosine ( $p$-Tyr). Representative immunoblots are shown. B) Immunoblots were quantified using ImageJ software; $p$-Tyr was normalized by FcRy $(n=3)$. Error bars represent the standard error of the mean and statistical significance was determined using one-way ANOVA with Tukey's multiple comparisons test. ${ }^{*} P<0.05,{ }^{* *} P<0.01$, compared to the untreated control. ${ }^{\#} P<0.05,{ }^{\#} P<0.01$ compared to $0.2 \mathrm{mM}$ coprostanol. All $P$-values were adjusted for multiplicity.

Figure 9. Cholesterol and sphingomyelin rich plasma lipid rafts are important for Fcy receptor mediated phagocytosis of $\boldsymbol{C}$. neoformans by macrophages. Upon binding IgG-based immune complexes comprised of anti-GXM antibody opsonized C. neoformans, Fcy receptor III (CD16) localizes to the plasma lipid rafts. A) When lipid rafts are enriched with raft-forming sterols (i.e., cholesterol and 7-dehydrocholesterol; only cholesterol shown for simplicity) or sphingomyelin (i.e., trans-AzoSM; only endogenous sphingomyelin shown for simplicity), the Fc receptor $\mathrm{Y}$ chain is properly phosphorylated to initiate the signaling cascade associated with phagocytosis. B) When lipid rafts are enriched with raft-inhibiting sterols such as coprostanol (right) or raft-disrupting sphingomyelin, cis-AzoSM (left), Fc receptor $\mathrm{Y}$ chain is not properly phosphorylated. 
A.

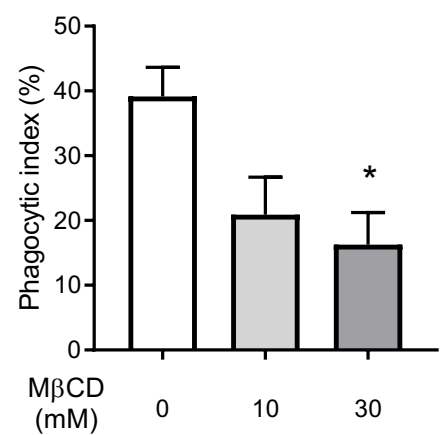

B.

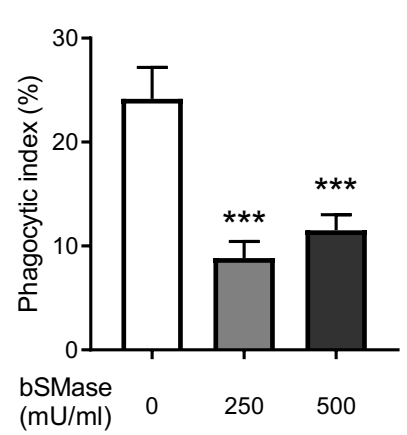

C.

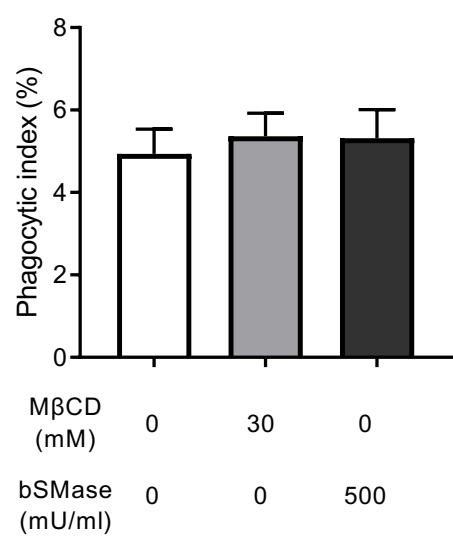

Figure 1. Cholesterol and sphingomyelin are important for antibody-mediated phagocytosis. A) Macrophages (MH-S) treated with either 10 or $30 \mathrm{mM}$ methyl-beta-cyclodextrin (MBCD) were coincubated with antibody-opsonized $C$. neoformans $\mathrm{H} 99$ at a 1:1 ratio and allowed to interact for 2 hours. Cells were then fixed and stained with Giemsa and phagocytic index was calculated by microscopic observation $(\mathrm{n}=4)$. B) Macrophages (MH-S) treated with either 250 or $500 \mathrm{mU} / \mathrm{ml}$ bacterial sphingomyelinase (bSMase) were co-incubated with antibody-opsonized $C$. neoformans $\mathrm{H} 99$ at a 1:1 ratio and allowed to interact for 2 hours. Cells were then fixed and stained with Giemsa and phagocytic index was calculated by microscopic observation (n=3). C) Macrophages (MH-S) treated with $30 \mathrm{mM} \mathrm{M \beta CD}$ or $500 \mathrm{mU} / \mathrm{ml}$ bSMase were coincubated with complement serum-opsonized C. neoformans $\mathrm{H} 99$ at a 1:1 ratio and allowed to interact for 3 hours. Cells were then fixed and stained with Giemsa and phagocytic index was calculated by microscopic observation $(n=4)$. Error bars represent the standard error of the mean (SEM), and statistical significance was determined using one-way ANOVA with Tukey's multiple comparisons test. ${ }^{*} P<0.05,{ }^{* * *} P<0.001$ compared to the untreated control. All $P$-values were adjusted for multiplicity. 


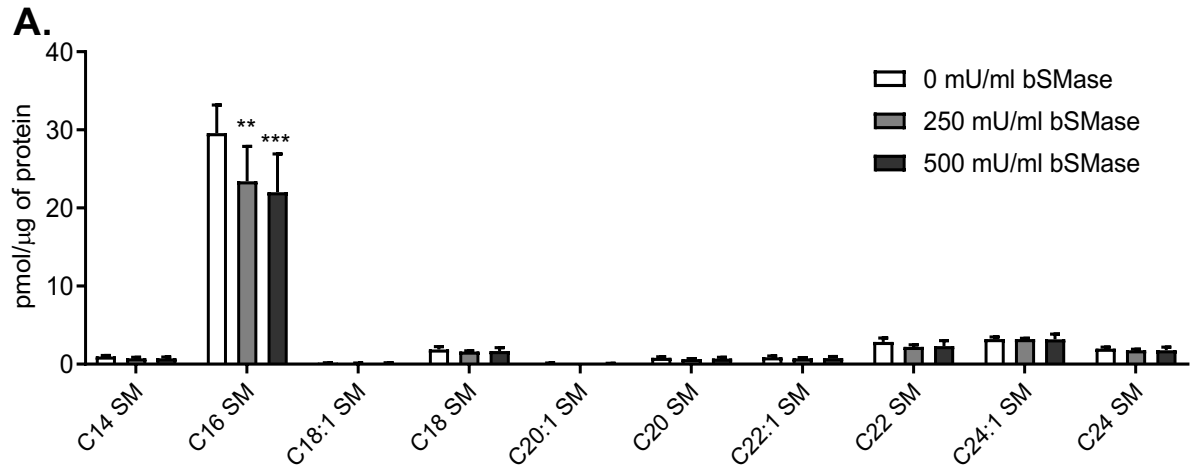

B.

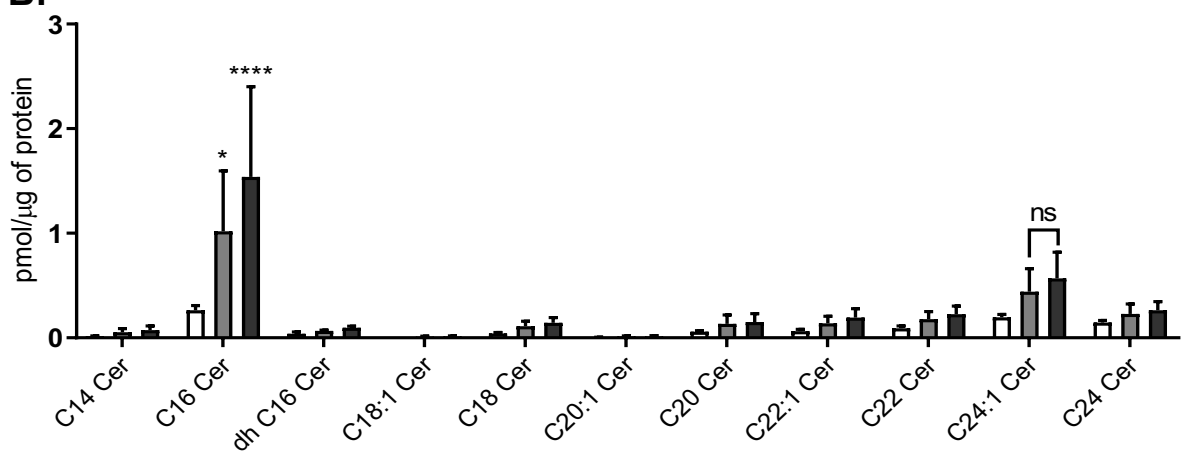

Figure 2. Measurement of sphingolipids after treatment with bacterial sphingomyelinase. Macrophages (J774.1) were treated with either 250 or $500 \mathrm{mU} / \mathrm{ml}$ bacterial sphingomyelinase (bSMase). Monolayers were then washed and subject to lipid extraction. Lipid extracts were then analyzed using liquid chromatography coupled mass spectrometry and normalized to protein found in the cell extract using the Bradford assay. A) Sphingomyelin (SM) species in the treated samples are shown $(n=3)$. B) Ceramide (Cer) species in the treated samples are shown $(n=3)$. Error bars represent the SEM and statistical significance was determined using ANOVA with Tukey's multiple comparisons test. Not significant (ns), ${ }^{*} P<0.05,{ }^{* \star} P<0.01,{ }^{* \star \star} P<0.005$, ${ }^{* * * *} P<0.0001$ compared to the untreated control. All $P$-values were adjusted for multiplicity. 
A. $\square$ cholesterol $\square$ 7-dehydrocholesterol

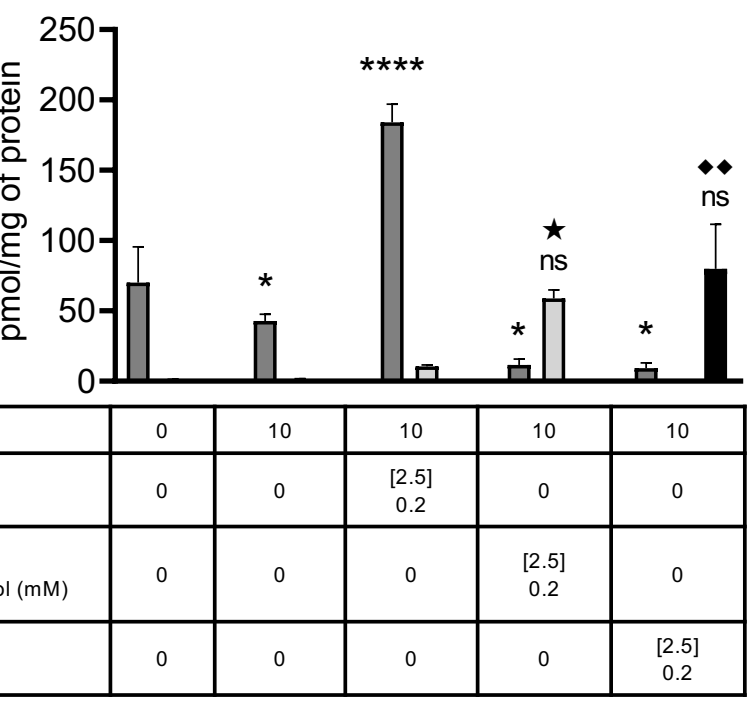

B.

$\square$ control

ש depletion only

$\square$ cholesterol

$\square$ 7-dehydrocholesterol

coprostanol

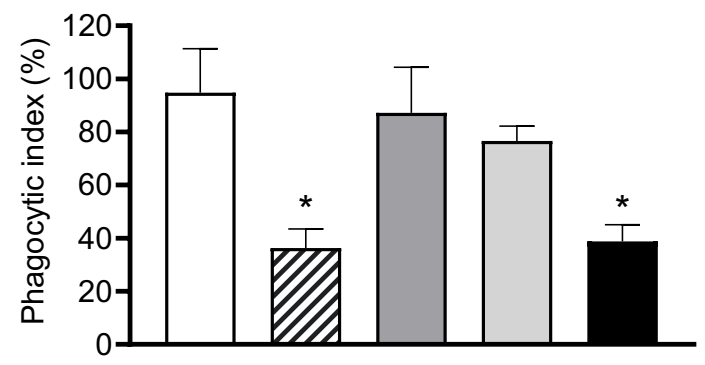

\begin{tabular}{|l|c|c|c|c|c|}
\hline $\mathrm{M} \beta \mathrm{CD}(\mathrm{mM})$ & 0 & 10 & 10 & 10 & 10 \\
\hline $\begin{array}{l}{[\mathrm{M} \beta \mathrm{CD}]} \\
+ \text { cholesterol }(\mathrm{mM})\end{array}$ & 0 & 0 & $\begin{array}{c}{[2.5]} \\
0.2\end{array}$ & 0 & 0 \\
\hline $\begin{array}{l}{[\mathrm{M} \beta \mathrm{CD}]} \\
+7 \text {-dehydrocholesterol (mM) }\end{array}$ & 0 & 0 & 0 & $\begin{array}{c}{[2.5]} \\
0.2\end{array}$ & 0 \\
\hline $\begin{array}{l}{[\mathrm{M} \beta \mathrm{CD}]} \\
+ \text { coprostanol }(\mathrm{mM})\end{array}$ & 0 & 0 & 0 & 0 & $\begin{array}{c}{[2.5]} \\
0.2\end{array}$ \\
\hline
\end{tabular}

Figure 3. Repletion with raft altering sterols affects phagocytosis. A) Macrophages (J774.1) were pre-treated with $10 \mathrm{mM} M \beta C D$ to deplete cholesterol and then washed and incubated with $2.5 \mathrm{mM} \mathrm{M \beta CD}$ loaded with $0.2 \mathrm{mM}$ of indicated sterol. Monolayers were then washed and subject to lipid extraction. Lipid extracts were then analyzed using gas chromatography coupled mass spectrometry and normalized to protein found in the cell extract by the Bradford assay ( $n=3)$. B) Macrophages were pre-treated with $10 \mathrm{mM} \mathrm{M \beta CD}$ to deplete cholesterol and then washed and incubated with $2.5 \mathrm{mM} \mathrm{MBCD}$ loaded with $0.2 \mathrm{mM}$ of indicated sterol. Monolayers were then washed and allowed to interact with antibody opsonized $C$. neoformans $\mathrm{H} 99$ at a 1:1 ratio for 2 hours. Cells were then fixed and stained with Giemsa and phagocytic index was calculated by microscopic observation $(n=3)$. Error bars represent SEM and statistical significance was determined using one-way ANOVA with Tukey's multiple comparisons test. Not significant (ns), ${ }^{*} P<0.05,{ }^{* *} P<0.01,{ }^{* * * *} P<0.0001$ compared to the cellular cholesterol for untreated control. ${ }^{\star} P<0.05$ compared to the cellular 7 -dehydrocholesterol for untreated control. $\bullet P<0.01$ compared to the cellular coprostanol for untreated control. All $P$-values were adjusted for multiplicity. 
A.

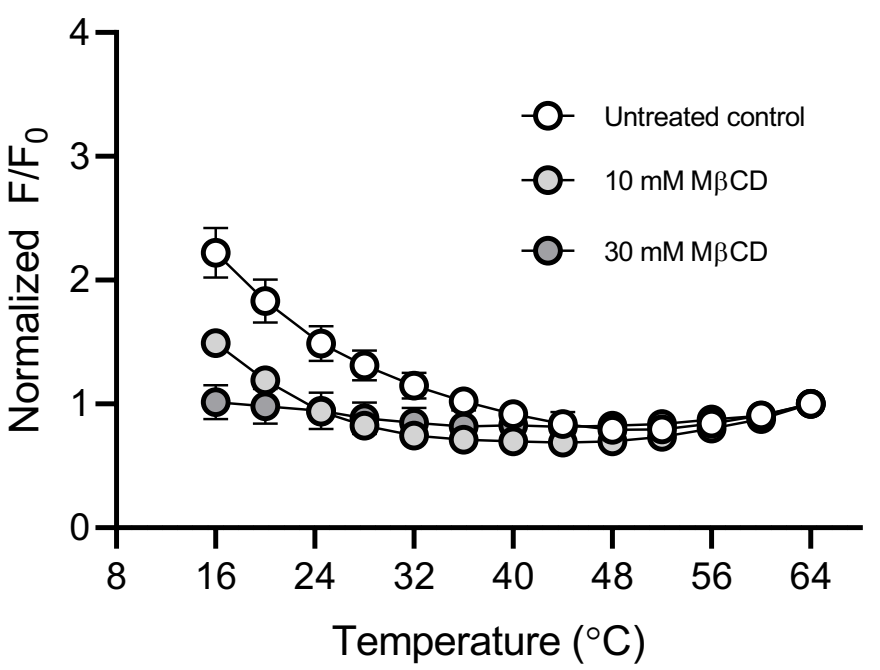

C.

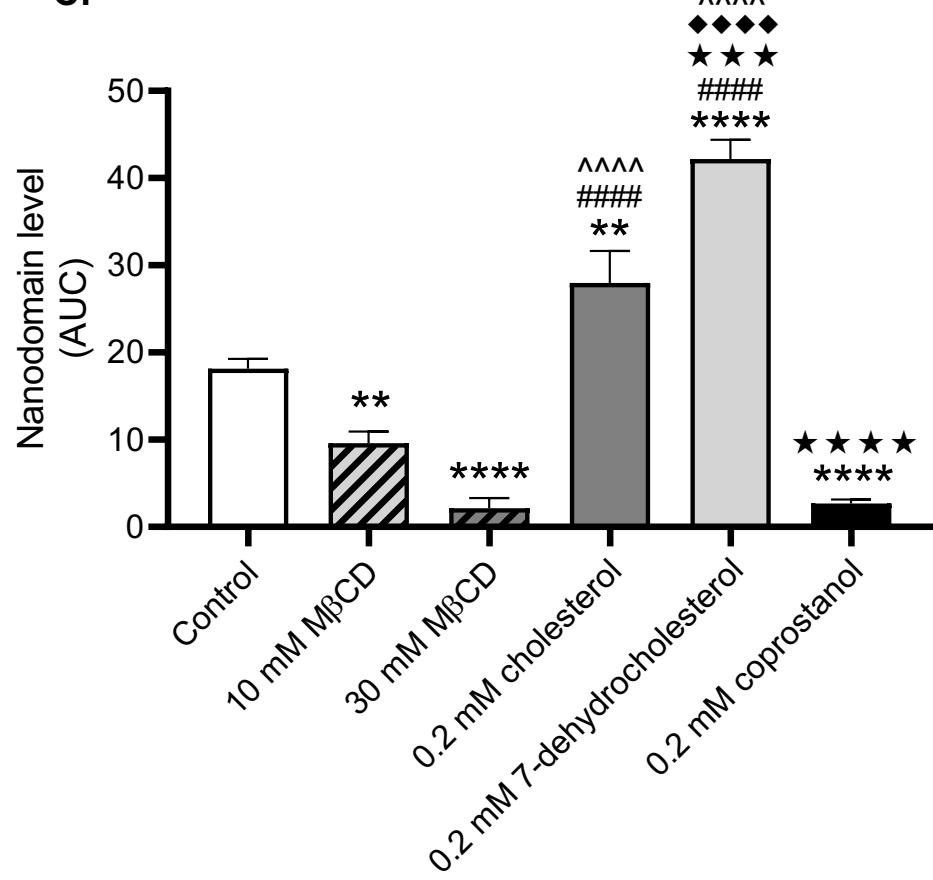

B.

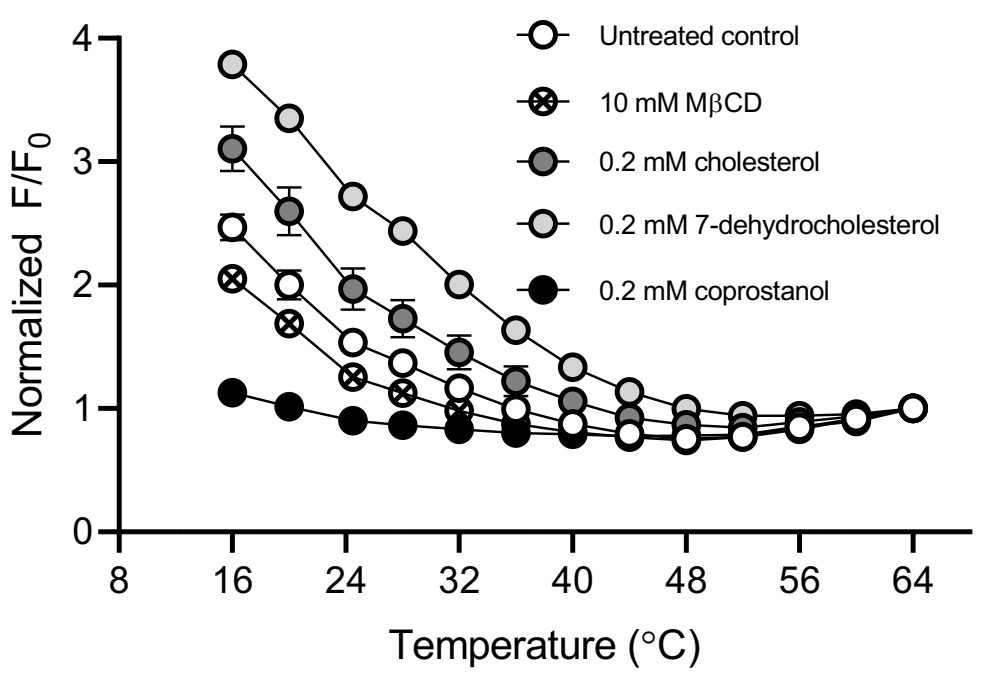

Figure 4. Repletion with raft altering sterols affects nanodomain stability. A) Macrophages (MH-S) were pre-treated with either 10 or 30 $\mathrm{mM} \mathrm{M} \beta \mathrm{CD}$ to deplete cholesterol. Monolayers were then washed and subject to giant plasma membrane vesicle formation using $25 \mathrm{mM}$ PFA and $2 \mathrm{mM}$ DTT. Nanodomain stability was assessed via FRET with DPH as the FRET donor and ODRB as the FRET acceptor. The ratio of DPH fluorescence intensity in the presence vs. absence of ODRB was calculated $\left(F / F_{0}\right)$. $F / F_{0}$ values were normalized to the final $F / F_{0}$ value at $64^{\circ} \mathrm{C}(\mathrm{n}=3)$. B) Macrophages were pre-treated with $10 \mathrm{mM} \mathrm{M \beta CD}$ to deplete cholesterol and then washed and incubated with $2.5 \mathrm{mM} \mathrm{M} \beta C D$ loaded with $0.2 \mathrm{mM}$ of indicated sterol. Monolayers were then washed and subject to giant plasma membrane vesicle formation using $25 \mathrm{mM}$ PFA and $2 \mathrm{mM}$ DTT. Nanodomain stability was assessed via FRET with DPH as the FRET donor and ODRB as the FRET acceptor. The ratio of DPH fluorescence intensity in the presence vs. absence of ODRB was calculated $\left(F / F_{0}\right)$. $F / F_{0}$ values were normalized to the final $F / F_{0}$ value at $64^{\circ} \mathrm{C}(\mathrm{n}=3)$. C) Relative domain levels were estimated using the polynomial fits from A \& B as described under Experimental procedures. Error bars represent SEM. Detectable nanodomains were compared using one-way ANOVA with Tukey's multiple comparisons test. ${ }^{* *} P<0.01$, ${ }^{* * *} P$

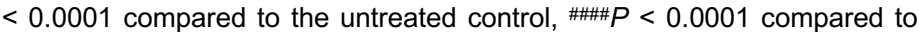
$10 \mathrm{mM} \mathrm{MBCD}, \wedge \wedge \wedge \wedge P<0.0001, \star \star \star P<0.001, \star \star \star \star x P<0.0001$ compared to $0.2 \mathrm{mM}$ cholesterol, and $\cdots P<0.0001$ compared to $0.2 \mathrm{mM}$ coprostanol. All $P$-values were adjusted for multiplicity. 


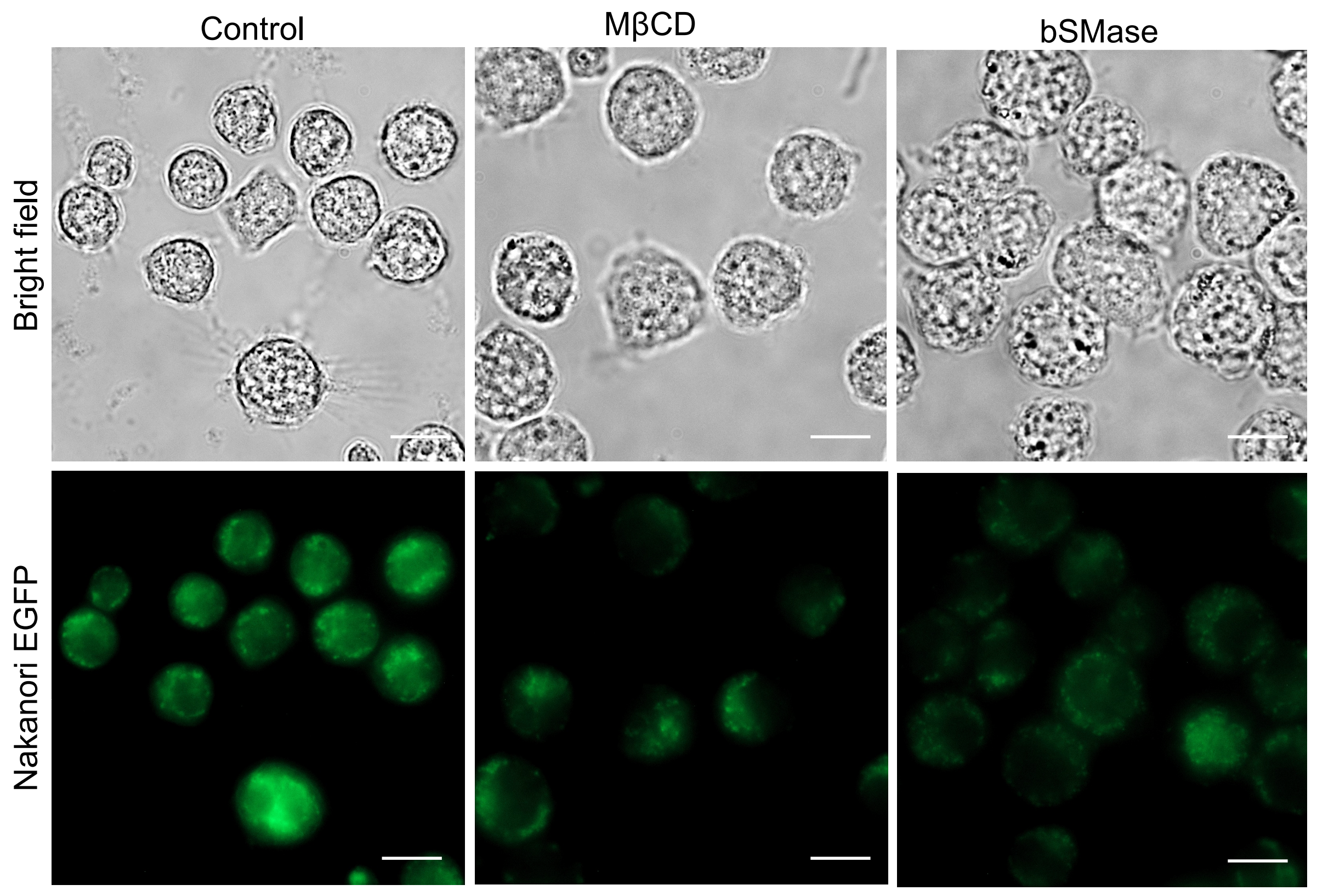

Figure 5. Nakanori labeling is affected by lipid altering treatments. Macrophages (MH-S) were adhered onto glass bottomed microscopy dishes. After treatment with $10 \mathrm{mM}$ $\mathrm{M} \beta C D$ or $250 \mathrm{mU} / \mathrm{ml}$ bacterial sphingomyelinase (bSMase) as described under Experimental Procedures, live macrophages were labeled with recombinant nakanori-EGFP and then fixed with $4 \%$ paraformaldehyde. Scale bar= $10 \mu \mathrm{m}$. 
A.

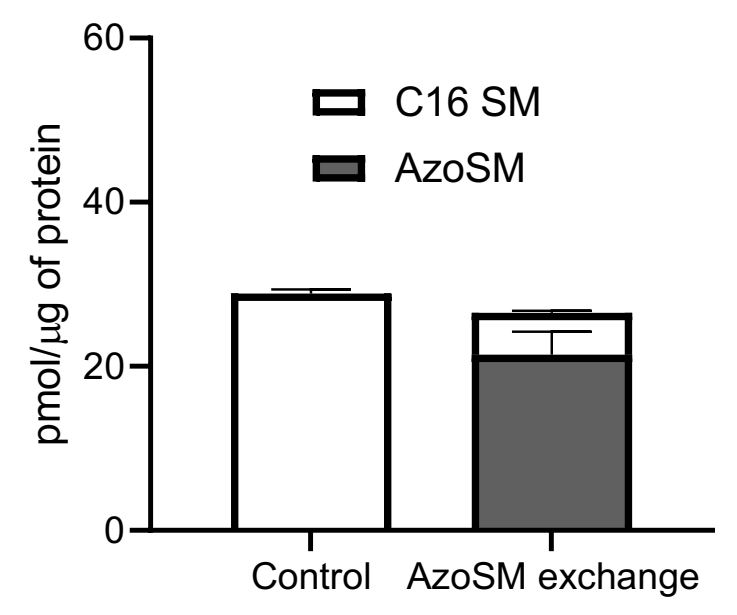

B.

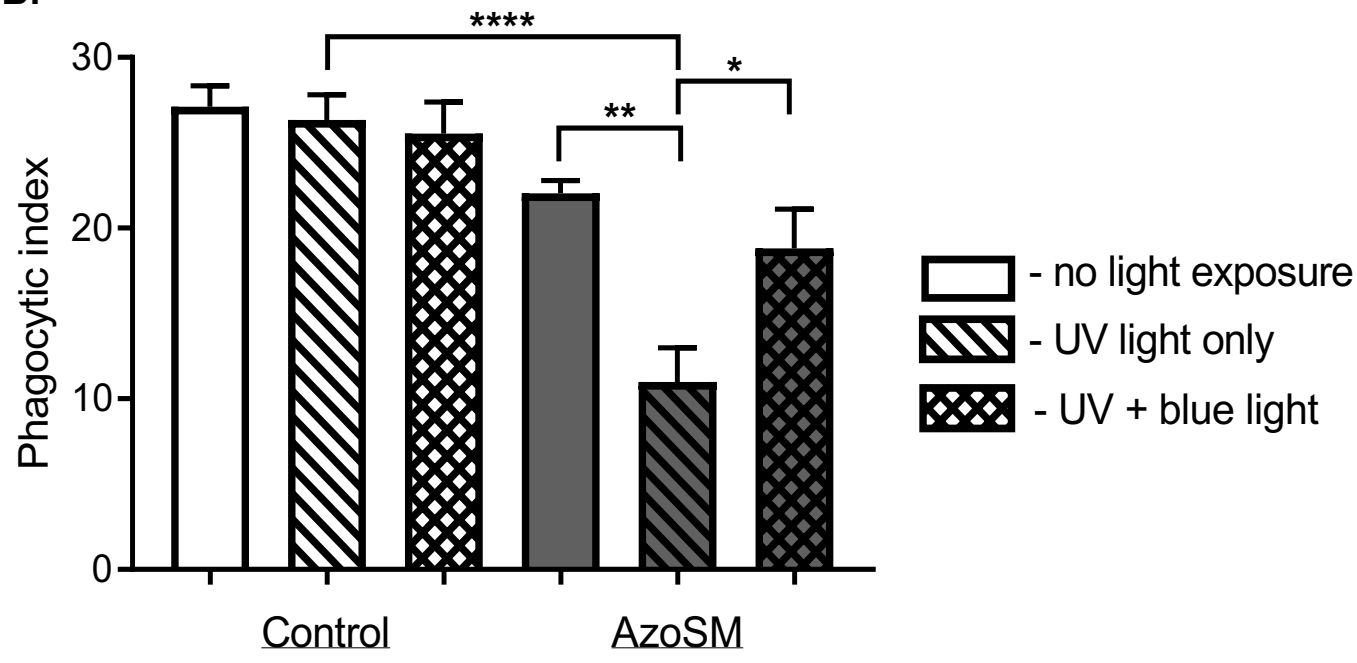

Figure 6. Exclusion of sphingomyelin from rafts affects phagocytosis $C$. neoformans. A) Macrophages (MH-S) treated with the AzoSM exchange protocol using MaCD as described in Experimental Procedures. Cell extracts were then evaluated for endogenous C16 sphingomyelin (C16 SM) using LC-MS and AzoSM using HPLC. Lipid content from each sample was normalized by protein content as determined using the Bradford assay ( $\mathrm{n}=3$ ) B) Macrophages (MH-S) treated with the AzoSM exchange protocol were either unexposed, exposed to UV light, or exposed to UV light followed by blue light. Control samples were mock treated. Washed monolayers were then co-incubated at a 1:1 ratio with $C$. neoformans $\mathrm{H} 99$ opsonized with $18 \mathrm{~B} 7$ antibody and allowed to interact for 30 minutes. Cells were then fixed and stained with Giemsa and phagocytic index was calculated by microscopic observation. Error bars represent the standard error of the mean and statistical significance was determined using two-way analysis of variance with Tukey's multiple comparisons test $(\mathrm{n}=4)$. ${ }^{*} P<0.05,{ }^{* *} P<0.01$, and ${ }^{* * * *} P<0.0001$. All $P$-values were adjusted for multiplicity. 


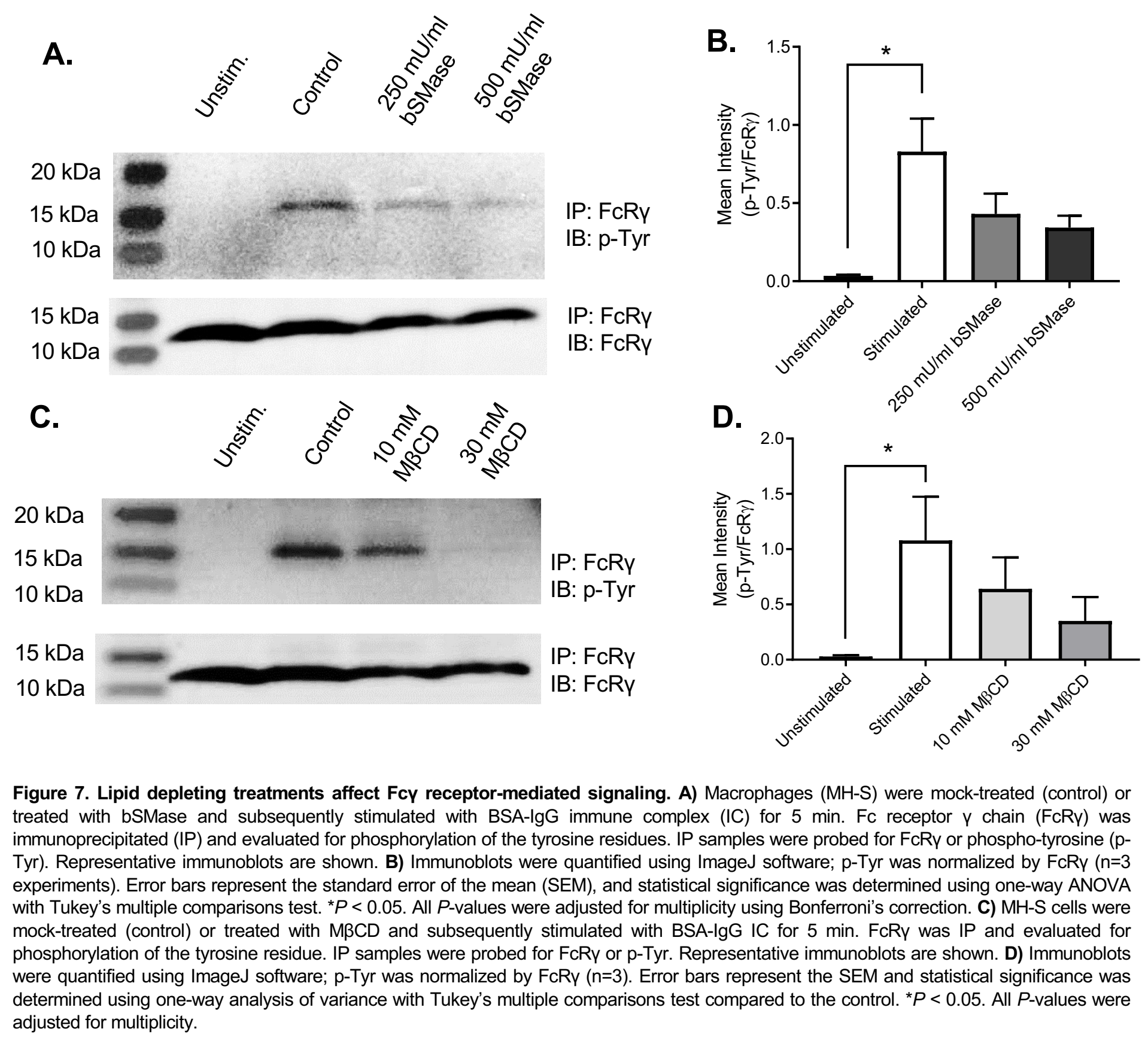


A.
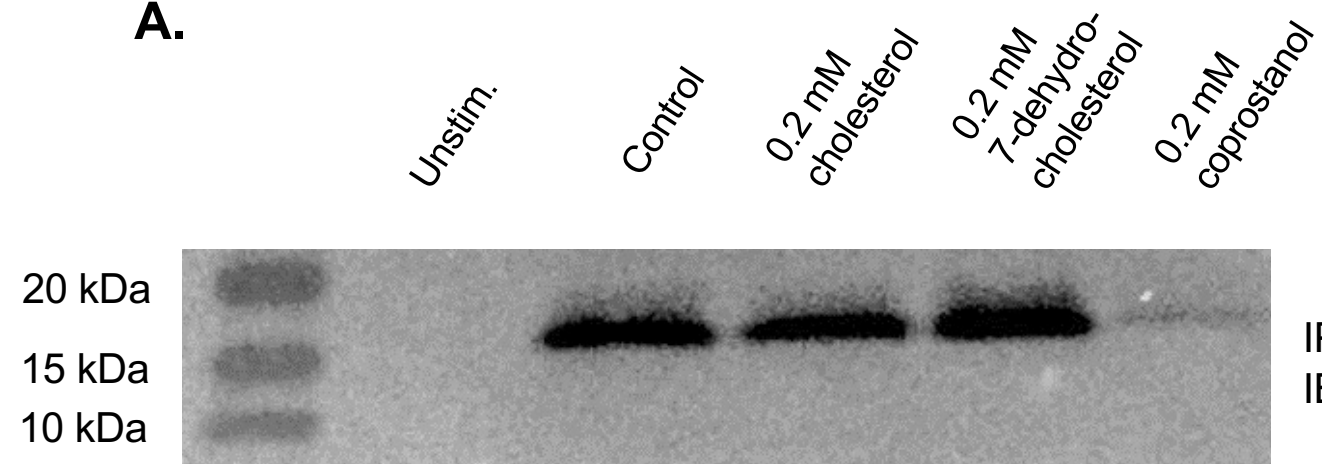

IP: FcRY

IB: $p-T y r$

$15 \mathrm{kDa}$

$10 \mathrm{kDa}$

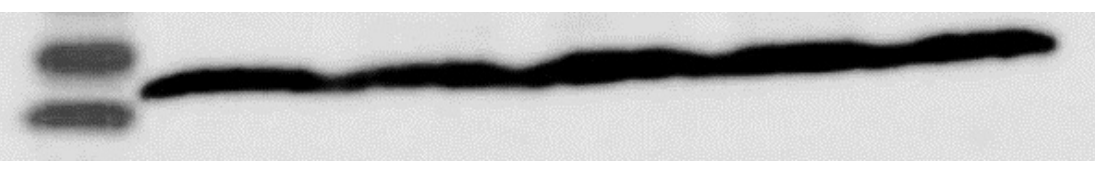

B.

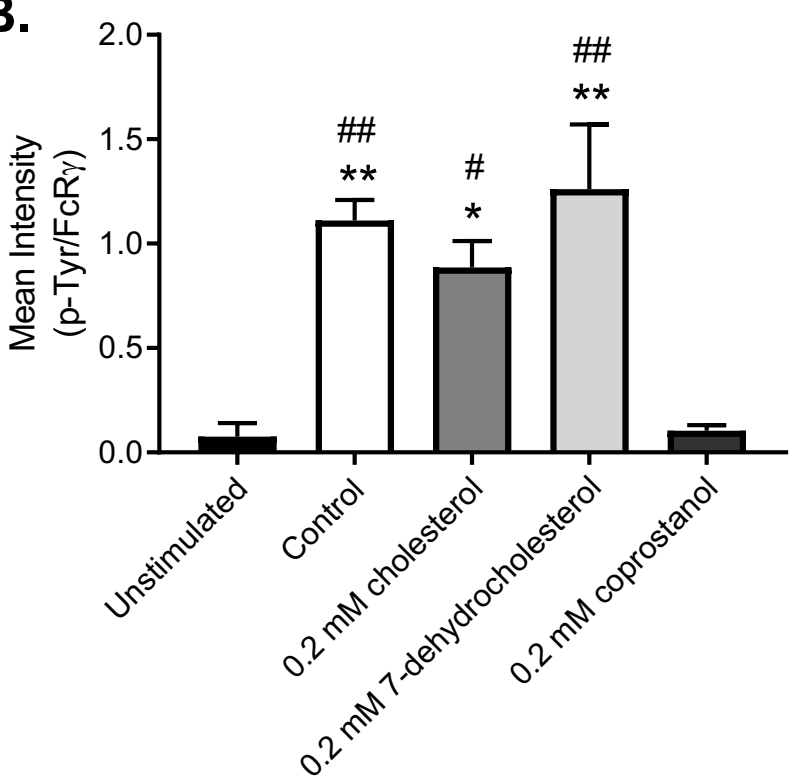

Figure 8. Repletion with raft-altering sterols affects Fcy receptor-mediated signaling. A) Macrophages were mock-treated (control) or pre-treated with $10 \mathrm{mM} M \beta C D$ to deplete cholesterol and then washed and incubated with $2.5 \mathrm{mM} \mathrm{MBCD}$ loaded with $0.2 \mathrm{mM}$ of indicated sterol. Cells were then stimulated with BSA-IgG immune complex (IC) for 5 min. Fc receptor $y$ chain ( $F c R y$ ) was immunoprecipitated and evaluated for phosphorylation of the tyrosine residue. IP samples were probed for FcRy or phospho-tyrosine ( $\mathrm{p}-\mathrm{Tyr}$ ). Representative immunoblots are shown. B) Immunoblots were quantified using ImageJ software; $p$-Tyr was normalized by FcRy $(n=3)$. Error bars represent the standard error of the mean and statistical significance was determined using one-way ANOVA with Tukey's multiple comparisons test. ${ }^{*} P<0.05,{ }^{* *} P<0.01$, compared to the untreated control. ${ }^{*} P<$ $0.05,{ }^{\#} P<0.01$ compared to $0.2 \mathrm{mM}$ coprostanol. All $P$-values were adjusted for multiplicity. 

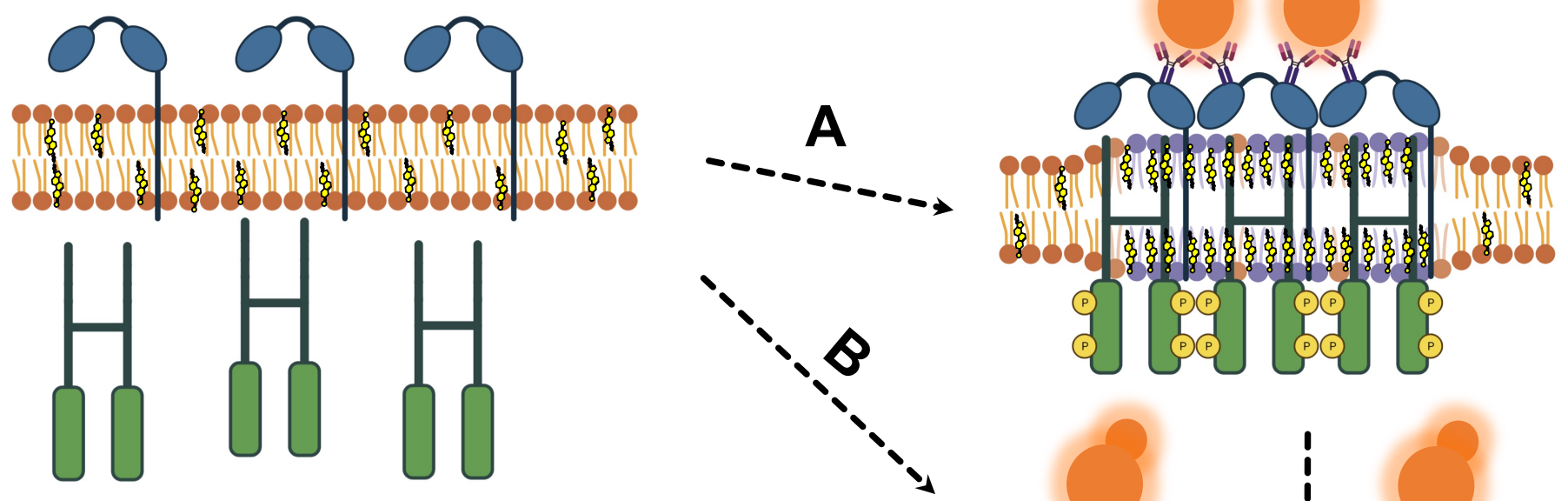

(3)


Figure 9. Cholesterol and sphingomyelin rich plasma lipid rafts are important for Fcy receptor mediated phagocytosis of $C$. neoformans by macrophages. Upon binding IgG-based immune complexes comprised of anti-GXM antibody opsonized C. neoformans, Fcy receptor III (CD16) localizes to the plasma lipid rafts. A) When lipid rafts are enriched with raft-forming sterols (i.e., cholesterol and 7-dehydrocholesterol; only cholesterol shown for simplicity) or sphingomyelin (i.e., trans-AzoSM; only endogenous sphingomyelin shown for simplicity), the Fc receptor $\mathrm{Y}$ chain is properly phosphorylated to initiate the signaling cascade associated with phagocytosis. B) When lipid rafts are enriched with raftinhibiting sterols such as coprostanol (right) or raft-disrupting sphingomyelin, cis-AzoSM (left), Fc receptor $y$ chain is not properly phosphorylated. 